\title{
Understanding the key elements for designing and implementing social marketing campaigns to inform the development of creative approaches for FGM/C abandonment in Sudan
}

Widad Ali A/Rahman

Samia Al Nagar

Randa H. Gindeel

Arwa Salah

Follow this and additional works at: https://knowledgecommons.popcouncil.org/departments_sbsr-rh

Part of the Demography, Population, and Ecology Commons, Family, Life Course, and Society

Commons, Gender and Sexuality Commons, and the International Public Health Commons

How does access to this work benefit you? Let us know!

\section{Recommended Citation}

A/ Rahman, Widad Ali, Samia Al Nagar, Randa H. Gindeel, and Arwa Salah. 2018. "Understanding the key elements for designing and implementing social marketing campaigns to inform the development of creative approaches for FGM/C abandonment in Sudan," Evidence to End FGM/C: Research to Help Women Thrive. New York: Population Council. 


\section{Evidence to \\ End FGM/C}

Research to Help Girls and Women Thrive

UNDERSTANDING THE KEY ELEMENTS

FOR DESIGNING AND IMPLEMENTING

SOCIAL MARKETING CAMPAIGNS

TO INFORM THE DEVELOPMENT

OF CREATIVE APPROACHES FOR

FGM/C ABANDONMENT IN SUDAN

October 2018 


\title{
UNDERSTANDING THE KEY ELEMENTS FOR DESIGNING AND IMPLEMENTING SOCIAL MARKETING CAMPAIGNS TO INFORM THE DEVELOPMENT OF CREATIVE APPROACHES FOR FGM/C ABANDONMENT IN SUDAN
}

\author{
WIDAD ALI A/ RAHMAN \\ SAMIA AL NAGAR \\ RANDA H. GINDEEL \\ ARWA SALAH
}

GENDER AND REPRODUCTIVE HEALTH AND RIGHTS RESOURCE CENTER

October 2018 
The Evidence to End FGM/C: Research to Help Girls and Women Thrive generates evidence to inform and influence investments, policies, and programmes for ending female genital mutilation/cutting in different contexts. Evidence to End FGM/C is led by the Population Council, Nairobi in partnership with the Africa Coordinating Centre for the Abandonment of Female Genital Mutilation/Cutting (ACCAF), Kenya; the Global Research and Advocacy Group (GRAG), Senegal; Population Council, Nigeria; Population Council, Egypt; Population Council, Ethiopia; MannionDaniels, Ltd. (MD); Population Reference Bureau (PRB); University of California, San Diego (Dr. Gerry Mackie); and University of Washington, Seattle (Prof. Bettina Shell-Duncan).

POPULATION COUNCIL

Ideas. Evidence. Impact.
The Population Council confronts critical health and development issues-from stopping the spread of HIV to improving reproductive health and ensuring that young people lead full and productive lives. Through biomedical, social science and public health research in 50 countries, we work with our partners to deliver solutions that lead to more effective policies, programmes and technologies that improve lives around the world. Established in 1952 and headquartered in New York, the Council is a non-governmental, non-profit organisation governed by an international board of trustees. www.popcouncil.org

The Gender and Reproductive Health \& Rights Resource Centre (GRACe) is a leading regional centre of excellence on gender and reproductive health and rights; Providing quality resources for all stakeholders, building capacities, promoting evidence-based planning and policy for empowering women and men and promoting reproductive health as a fundamental human right for all. GRACe values are gender equality, women empowerment, integrity, respect for human rights and excellence. It aims to promote gender equality and reproductive health and rights of the community in general and of women in Sudan and the region. www.grace.ahfad.edu.sd

Suggested Citation: A/Rahman, W., Alnagar, S., Gindeel, R. and Salah, A. October 2018. Understanding the Key Elements for Designing and Implementing Social Marketing Campaigns to Inform the Development of Creative Approaches for FGM/ C Abandonment in Sudan. Evidence to End FGM/C: Research to Help Girls and Women Thrive. New York: Population Council.

This is a working paper and represents research in progress. This paper represents the opinions of the authors and is the product of professional research. This paper has not been peer reviewed, and this version may be updated with additional analyses in subsequent publications. Contact: Widad Ali A/Rahman, widadali01@live.com.

Please address any inquiries about the Evidence to End FGM/C programme consortium to:

Dr Jacinta Muteshi, Project Director, imuteshi@popcouncil.org

Funded by:

This document is an output from a programme funded by the UK Aid from the UK government for the benefit of developing countries. However, the views expressed and information contained in it are not necessarily those of, or endorsed by the UK government, which can accept no responsibility for such views or information or for any reliance placed on them. 


\section{Table of Contents}

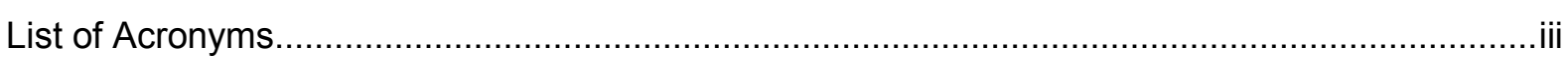

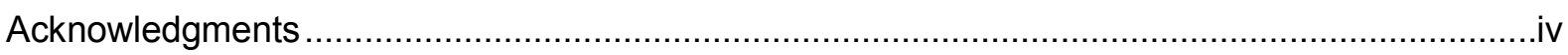

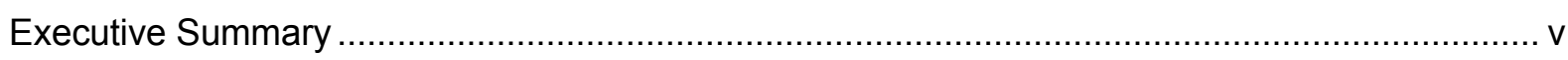

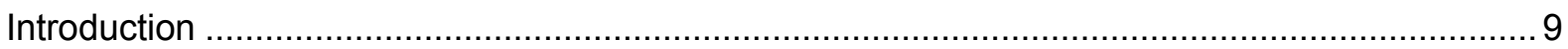

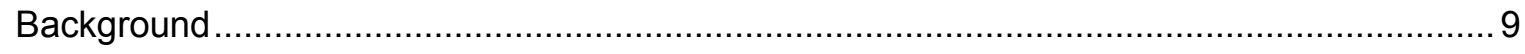

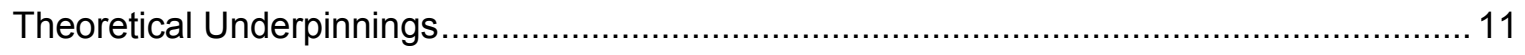

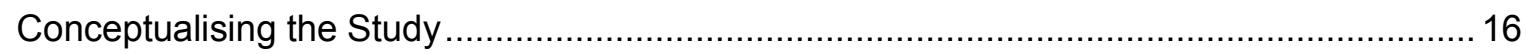

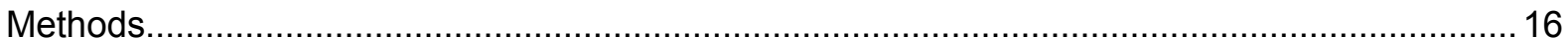

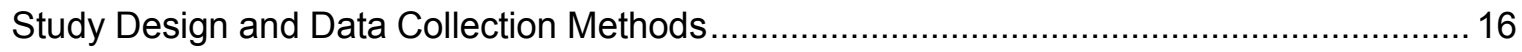

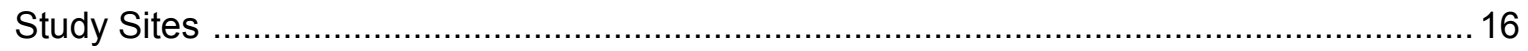

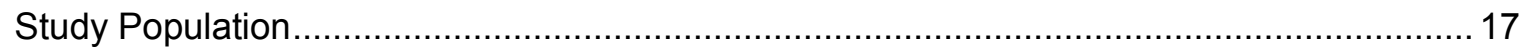

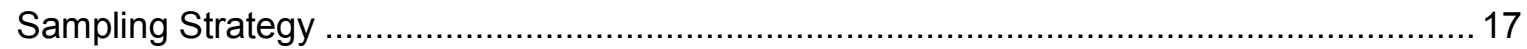

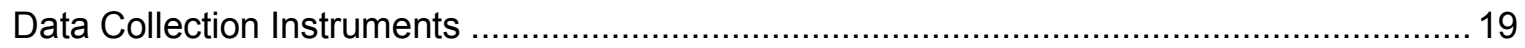

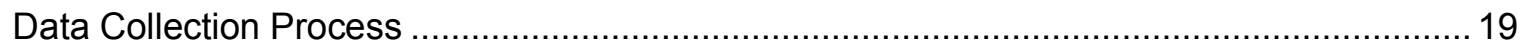

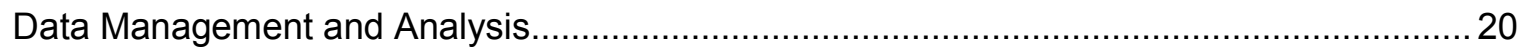

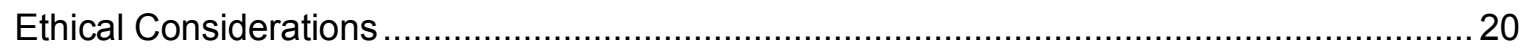

Findings

Design and Implementation of Social Marketing Campaigns for FGM/C Abandonment........ 21

Use of Theory and Alignment with Andreasen's (1994) Checklist of Best Practices in Social

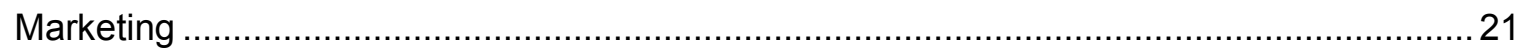

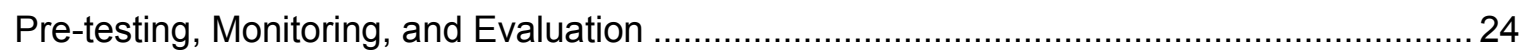

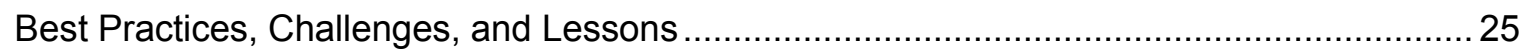

Community Perceptions of FGM/C Abandonment Interventions ........................................... 26

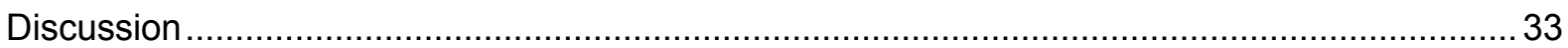

Implications for Practice, Funding, Research, and Policy ........................................................ 36

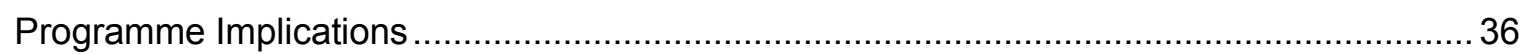

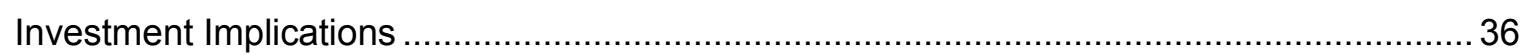

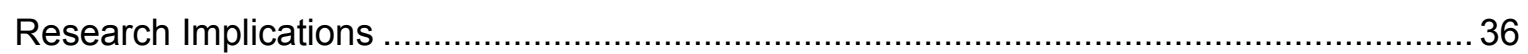

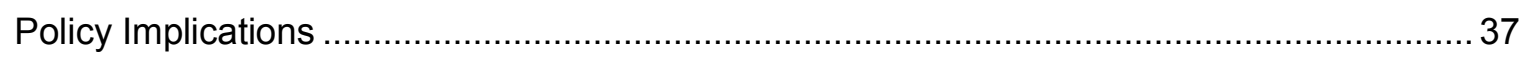

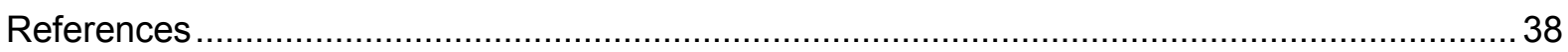




\section{List of Acronyms}

\begin{tabular}{|c|c|}
\hline AUW & Ahfad University for Women \\
\hline CBO & Community Based Organisation \\
\hline CCD & College for Community Development \\
\hline C/VAW & Consortium of Violence Against Women \\
\hline CPA & Comprehensive Peace Agreement \\
\hline DfID & Department for International Development \\
\hline FGD & Focus Group Discussion \\
\hline $\mathrm{FGM} / \mathrm{C}$ & Female Genital Mutilation/Cutting \\
\hline $\mathrm{FMoH}$ & Federal Ministry of Health \\
\hline FPDO & Friendship of Peace and Development Organization \\
\hline GBV & Gender-Based Violence \\
\hline GRACe & Gender and Reproductive Health \& Rights Resource Centre \\
\hline KII & Key Informant Interview \\
\hline M\&E & Monitoring and Evaluation \\
\hline MoGE & Ministry of Guidance and Endowment \\
\hline MICS & Multiple Indicators Cluster Survey \\
\hline MoWSS & Ministry of Welfare and Social Security \\
\hline$M \& R$ & Almawada wa Al-Rahma \\
\hline NCCW & National Council for Child Welfare \\
\hline NGO & Non-Governmental Organisation \\
\hline $\mathrm{PI}$ & Principal Investigator \\
\hline SHHS & Sudan Household Survey \\
\hline SM & Social Marketing \\
\hline SMC & Social Marketing Campaign \\
\hline UN & United Nations \\
\hline UNFPA & United Nations Population Fund \\
\hline UNICEF & United Nation Children's Fund \\
\hline WHO & World Health Organization \\
\hline
\end{tabular}




\section{Acknowledgments}

The authors thank Nafisa Bedri from the Gender and Reproductive Health \& Rights Resource Centre at the Ahfad University for Women; Balghis Badri from the Regional Institute for Gender, Diversity, Peace and Rights at the Ahfad University for Women; Hazel Barrett from Coventry University; Gerry Mackie from the University of California, San Diego; and Jacinta Muteshi and Caroline Kabiru from the Population Council for their expert review and critique of this report.

We also extend our gratitude to the study populations, institutions and administrative authorities in the surveyed localities for their cooperation and support to this effort. Lastly, the authors extend their sincere appreciation to the Population Council Project Team in Nairobi, New York, and Washington D.C. for their overall support and prompt response to addressing the study needs and the editing support provided to finalise this report. 


\section{Executive Summary}

\section{Background}

Sudan ranks fifth in the prevalence of female genital mutilation/cutting (FGM/C). Despite a growing number of $\mathrm{FGM} / \mathrm{C}$ abandonment programmes, the practice remains widespread with over 80 percent of girls and women aged 15-49 years having undergone FGM/C. As a socially sanctioned practice, $\mathrm{FGM} / \mathrm{C}$ is underpinned by several normative justifications around marriage, female sexuality, hygiene, beauty and, more broadly, womanhood. Therefore, those engaged in programmes and activities towards the abandonment of FGM/C have encouraged the application of social marketing (SM) concepts as an innovative approach towards changing social norms that perpetuate the practice.

FGM/C abandonment SM initiatives include the Saleema Campaign, which aims to strengthen existing or new positive values for girls and women within society. The campaign grew out of the recognition of a critical language gap in colloquial Sudanese Arabic, which does not include a positive term for an uncut woman or girl. The initiative introduced the term 'Saleema' - a positive term for an uncut girl that portrays her as whole, healthy, and complete. The campaign uses different communication tools to mobilise communities to shift away from traditional practices and beliefs to new social norms by using positive language and messages.

Another SM initiative, Almawada wa Al-Rahma (M\&R), which translates to affection and mercy, uses social norms change strategies to help community and religious leaders relate to values on affection and mercy in anti-FGM/C campaigns. The M\&R campaign is defined as a 'social reform' approach that focuses primarily on reviving the faith-based and positive indigenous 'values' of Sudanese society as entry points to transform 'harmful social norms' that affect individuals, persons with no support, and groups at risk. The initiative draws on Islamic values to counteract and change the negative perceptions and attitudes of target communities on gender-based violence (GBV) issues, including FGM/C.

While social marketing campaigns (SMCs) have gained prominence in abandonment efforts, there is a dearth of information on how these programmes are designed and implemented, and their perceived impact. Understanding the implementation process and the effectiveness of these campaigns is critical for drawing lessons to improve existing programmes and inform the design and scale up of SMCs in other regions/countries. This mixed method study sought to address this gap by assessing the design and implementation of existing SMC programmes in Sudan. The study's specific objectives were to:

- Examine the design and implementation processes of anti-FGM/C SMC initiatives in two states: Khartoum and Gedaref;

- Identify the challenges, promising practices, and lessons learned that emerge during the development and implementation of these initiatives; and

- Assess communities' exposure to FGM/C abandonment messages, their perception about these, and whether these messages have influenced attitudes towards $F G M / C$ abandonment.

\section{Methods}

The study used a cross-sectional design with mixed qualitative (key informant interviews [KIIs], indepth interviews [IDIs] and focus group discussions [FGDs]) and quantitative (household surveys and observations) methods. The use of mixed methods allowed for richer in-depth exploration of the design and implementation processes of SMCs and assessment of target audiences' exposure to $\mathrm{FGM} / \mathrm{C}$ abandonment messages and their perceptions about the influence of SM messages on abandonment decisions. 
The study was conducted in two purposively selected states, Khartoum and Gedaref, that host a diverse group of actors involved in FGM/C abandonment interventions. The study population comprised representatives from different organisations that were involved in the design and implementation of SMCs, donor organisations, and the wider community in areas where antiFGM/C interventions have been implemented.

A total of $22 \mathrm{KIls}$ were conducted with top level officials who were closely engaged in the design and/or implementation of interventions for FGM/C abandonment. Key informants were identified by representatives from targeted organisations. Nine IDIs were conducted with men and women who had participated in FGM/C-related trainings and other activities organised as part of the SMCs. Eight FGDs (4 with men and 4 with women) were held with community members in localities targeted by the SMCs. Participants in the group discussions $(\mathrm{N} \sim 56)$ were purposively selected with support from field coordinators to ensure adequate representation based on key demographic variables. A total of 724 men and women in both states completed the quantitative survey. Survey respondents were selected using multistage cluster sampling in localities where SMCs had been implemented.

\section{Findings}

The study revealed that a variety of interventions to end FGM/C had been designed and implemented by diverse actors from as early as the 1970s. However, SM interventions were noted to be a recent introduction. Interviews with key informants highlighted several strengths and limitations of existing interventions. With respect to strengths, study findings demonstrate the central value placed on partnerships between multiple stakeholders and the recognition of the need to consider the target audiences' needs and wants to ensure that campaigns were readily acceptable and relevant. However, the interviews with key informants suggested that most interventions were not guided by an explicit theory of change. Both the Saleema and M\&R campaigns accounted for key aspects of an SM approach and incorporated some of the major elements of the marketing mix including formative work to understand the target audience as well as the creation of partnerships to facilitate implementation.

Further, the interviews with key informants revealed that SMCs were primarily focused on changing the behaviour of individuals at the 'downstream' level (i.e., community members) with few interventions including advocacy efforts targeted to 'upstream' audiences such as policy makers, who are responsible for formulating enabling policies. Further, pre-testing, monitoring, and evaluation were not well articulated in discussions with key informants. Lack of funding was highlighted as a key challenge to the effective delivery of SMCs.

Most SMC designers and implementers used multiple channels including non-print mass media, printed media, and inter-personal communications (e.g., community dialogues) to deliver messages to the target audiences. Not surprisingly, therefore, results of the quantitative survey among men and women in the study areas revealed high levels of public exposure to FGM/C abandonment messages. Survey respondents were more aware of messages expressing health harms with relatively few noting legal restrictions about $F G M / C$ or making reference to religious norms around FGM/C. A higher proportion of survey respondents were aware of Saleema's positive messages than the M\&R initiative. A significant number of respondents $(70 \%-100 \%)$ reported that they had decided to abandon FGM/C after exposure to anti-FGM/C messages.

\section{Discussion}

In response to the Sudanese government's endorsement of the eradication of FGM/C, several nationwide campaigns to encourage FGM/C abandonment have been implemented. While the study findings demonstrate several strengths of existing programmes, including strong 
partnerships and extensive needs assessments, they also highlight several gaps in the design and implementation of SMCs.

First, several scholars have argued that the design and evaluation of interventions, such as SMCs, should be guided by a theory of change that outlines the variables to be measured or changed as well as the pathways of change. This study found a limited application of theory in the design and implementation of many FGM/C campaigns. The limited use of theory and SM principles may be attributed to the relatively limited experience with SM approaches and lack of capacity building programmes that ensure that those who develop and implement these campaigns understand the theoretical and conceptual foundations of SMCs in addition to social norms and behaviour change theories.

Second, although pre-testing, monitoring, and evaluation are core to the application of the SM approach, most key informants noted that these aspects were not adequately addressed during the design and implementation of many campaigns. Limited knowledge about the principles and steps of the application of the SM approach may underlie the limited use of pre-tests to ensure relevance and suitability of FGM/C messages to people's needs and perception of $\mathrm{FGM} / \mathrm{C}$. Inadequate monitoring and evaluation (M\&E) may stem from several factors including organisational cultures that downplay its importance, low prioritisation because M\&E systems are often not a pre-requisite for funding of interventions, and limited capacity to design and implement M\&E systems.

Third, an important element of SMCs is the segmentation of audiences at three levels - upstream (policy makers, media, etc. who can create enabling environments), midstream (influencers such as friends and role models), and downstream (individuals engaged in the action to be changed). With a few notable exceptions, few of the campaigns focused on 'midstream' and 'upstream' actors, including political leaders, religious institutions, policy makers, and other stakeholders, who can serve as role models and play a major role in influencing policy change towards abandonment. Further research is needed to understand how programmes can create complementarity of interventions at the three levels.

\section{Implications of study findings for practice, funding, research, and policy}

\section{Programmatic implications}

Study findings highlight the need to strengthen programmatic aspects of SMCs to ensure quality and adequate reach. To improve programmatic design, delivery, and reach, programmes should:

- Invest in strengthening the capacity of staff to use marketing concepts and ensure that programmes are designed based on SMC principles, as well as effectively monitored and evaluated.

- Target individuals/institutions/organisations at midstream and upstream levels to create an enabling environment for behaviour change and ensure support at policy levels for FGM/C abandonment.

- Maintain and strengthen existing partnerships as well as establish new ones to ensure that partners work in a coordinated manner while considering the potential for innovation and diversification inherent in engaging with emerging new and young actors, such as youth organisations.

\section{Investment implications}

Study findings underscore the need for increased funding to ensure quality outreach and inclusion of individuals and communities for FGM/C abandonment. To address funding shortfalls, there is a need for: 
- Existing or potential donors interested in contributing to FGM/C abandonment work to commit to predictable, longer-term, and coordinated financing.

- The leading government institutions to raise funds from national and state governments and public institutions to demonstrate political will and reduce dependency on donors.

- Non-governmental organisations to develop fund-raising strategies that include outreach to the private sector to motivate them to contribute financially to these endeavours as part of corporate social responsibility.

\section{Research implications}

Study findings highlight some gaps for further research. These include:

- Research on how programmes can ensure complementarity of interventions at the upstream, midstream, and downstream levels.

- Research on the application of branding theories to SM programmes, given the important role that branding may play.

- In-depth analysis and understanding of the holistic approaches that respond to community needs while integrating $\mathrm{FGM} / \mathrm{C}$ abandonment in development programmes to inform replication and scale up.

- Further assessment of the potential for using social media and chat rooms on mobile phones as a communication channel.

Policy Implications

While at the individual level policy makers may be role models and positive influencers within their networks and communities, study findings suggest a need for consistent policies that create an enabling environment for the abandonment of all forms of FGM/C. Importantly, the need remains for:

- The enactment of an anti-FGM/C law.

- The formulation of a national funding strategy that supports policy change. 


\section{Introduction}

\section{Background}

Female genital mutilation/cutting (FGM/C) refers to 'all procedures involving partial or total removal of the female external genitalia, or other injury to the female genital organs for nonmedical reasons' (WHO 2014). Sudan ranks fifth among countries with FGM/C practice (UNFPA 2012). With a few exceptions, FGM/C is widespread across the country's different regions (Thiam 2016). The 2014 UNICEF Multiple Indicator Cluster Survey (MICS) in Sudan found an 86.6 percent $\mathrm{FGM} / \mathrm{C}$ prevalence rate for girls and women 15 to 49 years old. This rate is slightly higher in rural areas (87.2\%) as compared to urban areas (85.5\%) and varies across states. There are states with a high prevalence rate above 90 percent, such as in White Nile and North Kordofan $(97.7 \%)$. The prevalence rate in other states ranges from $87.5 \%$ in Khartoum, $89 \%$ in Red Sea, 78.5 percent in Gedaref, and 81 percent in West Kordofan to 45.5 percent in Central Darfur. This variation in the practice among the states reflects the presence of ethnic groups who do not follow the practice (Thiam 2016). The forms of FGM/C also vary: Type I, known as "Sunna" in the country, is the total or partial removal of the clitoris and the removal of the skin around the clitoris (the prepuce); Type II is the removal of the clitoris and part of the labia minora (excision) and labia majora; Type III, referred to as the Pharaonic in Sudan, is the narrowing of the vaginal opening (infibulation); and Type IV, which includes all other harmful procedures to the female genitalia for non-medical purposes, for example: pricking, piercing, incising, scraping, and cauterisation (WHO 2017).

Among practising groups, FGM/C occurs across all socio-economic classes, and in both rural and urban areas. The Sudan Household Survey (SHHS 2006 and 2010) and MICS (2014) show variations in prevalence of the practice by social demographic characteristics such as age, level of education, and economic status. Prevalence is 91.6 percent among those 40 to 49 years of age compared to 81.6 percent for 15- to 19-year-olds; 88 percent among poorest households compared to 91.6 percent among richer ones; and 84.2 percent among never married women, compared to 87.6 percent among currently married women (Thiam 2016).

In Sudan, families and communities that practise FGM/C believe it ensures the virginity of young girls, which is a prerequisite for marriageability. It is also believed to curb the sexual desire of girls, ensure premarital chastity and thus protect family honour. Furthermore, FGM/C is associated with cleanliness, ideas of beauty, and with purity of body, which are also requirements for marriage, reproduction, and a girl's preparation for womanhood and childbearing (Boddy 1982; Gruenbaum 2001). Moreover, there are social mechanisms of positive and negative sanctions, which control adherence to the practice as a shared norm. The sanctions for non-compliance include stigmatisation of girls, referring to uncut girls as 'Ghalfa'-a Sudanese term for a girl who is not cut, which is associated with impurity and promiscuity. Girls who are not cut are perceived to be prone to immorality thus risking their marriageability and their families' honour (Ahmed et al 2009).

Since the late 1970s, efforts in Sudan to support the abandonment of FGM/C have mainly been initiated by civil society organisations. These efforts have focused on awareness creation of the harmful health consequences associated with $\mathrm{FGM} / \mathrm{C}$ practice, delinking the practice from religion, and calling for legislation against FGM/C. In addition, occasional media coverage supported ending the practice. These efforts were often challenged by religious groups that support the practice and have political influence. Research has also been carried out by government institutions, international agencies/organisations, and universities to provide evidence to support the abandonment of FGM/C (Ahmed et al 2009). The outcomes of these early efforts have, however, been limited as these interventions and approaches did not achieve the aim of ending this deeprooted tradition (Sahl 2016). This may be attributed to limitations in the approaches and 
methodologies used and limitations in how behaviour change was understood and conceptualised. It could also be attributed to the power of conservative groups that advocated, through community media and education platforms, for what they deemed as the "Sunna" type of FGM/C. Bedri (2012) also noted that efforts have been fragmented and argued for an inclusive approach that considers introducing alternative norms to 'cutting' with relevant messages, means, and methods delivered through reliable and trusted sources for FGM/C elimination efforts.

The practise of FGM/C has been part of the country's political agenda for several years, with widespread mobilisation in support of abandonment and criminalisation of the practice. Increased momentum arose with the 2005 signing of the Comprehensive Peace Agreement (CPA), between the government and Sudan People's Liberation Movement, to end civil war in the south. The CPA included the promotion of human rights in the country in its agenda. This commitment encouraged the National Council for Child Welfare (NCCW) to prioritise FGM/C as a child protection issue and mobilise government institutions and non-governmental organisations (NGOs) at the national level to work on abandonment (Ahmed et al 2009, Bedri 2012). These efforts resulted in the government's endorsement of the National Strategy for Eradication of FGM/C in a Generation (2008-2018) and saw laws, albeit weak ones, banning the practice in four states.

With this new impetus, Sudan has witnessed nationwide campaigns to encourage FGM/C abandonment with more inclusive approaches and the adoption of social marketing (SM) principles and tactics. As a socially sanctioned practice, $F G M / C$ is underpinned by several normative justifications around marriage, female sexuality, hygiene, beauty and, more broadly, womanhood. Those engaged in programmes and activities towards the abandonment of FGM/C have encouraged the application of SM concepts as an innovative approach towards changing social norms. The SM approach was introduced at a critical political time after the signing of the CPA, which created an environment for democratic governance and peace building. The Saleema Initiative (http://saleema.net/saleema initiative.php) is one such communication campaign that was launched in 2008. The initial idea for the Saleema social marketing campaign (SMC) began in 2005, when the NCCW in Khartoum State requested UNICEF to design a campaign for child protection in the war zones. The campaign adopted a participatory and dynamic method for prioritising child protection on a variety of issues including $\mathrm{FGM} / \mathrm{C}$, child soldiers, abandoned children, forced marriages, corporal punishment, and sexual abuse. The project began with formative research to explore the knowledge and attitudes of people about the links between FGM/C and child protection. From that research, an idea was born to change the negative terminology that described uncut girls and causes stigma. Saleema-a positive term for the uncut that portrays her as whole, healthy, and complete-uses several different communication tools to mobilise communities to shift away from traditional practices and beliefs to new social norms, by using positive language and messages. Saleema is viewed as a better approach to replace and, in some contexts, complement previous efforts through the adoption of an SM approach towards social norm change.

Another SM initiative, Almawada wa Al-Rahma (M\&R), which translates to affection and mercy, uses social norms change strategies to help community and religious leaders to relate to the values of affection and mercy in anti-FGM/C campaigns. The M\&R, which was launched and led by the Ministry of Guidance and Endowment in 2012 and supported by UNFPA, is defined as a 'social reform' approach. It focuses primarily on reviving the faith-based and the positive indigenous 'values' of Sudanese society as entry points to transform 'harmful social norms' that affect individuals, persons with no support, and groups at risk. The initiative draws on Islamic values to counteract and change the harmful perceptions and attitudes of target communities on genderbased violence (GBV) issues, including FGM/C, child marriage, gender relations, marriageability, and sexuality. Emphasis is placed on delinking harmful practices from religion (Sahl 2016). The 
M\&R approach also seeks to complement other intervention approaches as it addresses the health, religious, social, cultural, rights, and legal perspectives of the practice.

Since 2008, when the first SMC was applied to FGM/C interventions, many stakeholders have become involved in abandonment efforts with the bulk of their resources being allocated to SMCs. These efforts appear to have succeeded in breaking the silence on the practice. For example, while there has been little change in the prevalence of the practice among girls and women aged 15 to 49 years-87.6 percent in 2010 (SHHS 2010) and 86.6 percent in 2014 (MICS 2014), the percentage of women ages 15 to 49 years that support continuation of the practice dropped from 48.1 percent in 2010 (SHHS 2010) to 40.9 percent in 2014 (MICS 2014). Further, the Department for International Development (DfID) Sudan's opinion poll data (2012 to 2014) showed a decrease in the overall proportion of people who were pro-FGM (27.5\% to $18.3 \%)$, with striking variations within states (Hamilton and Kandala 2015). In addition, the MICS 2014 results showed that at the national level, 14.2 percent of women used the positive term 'Saleema' in reference to uncut girl with significant urban-rural differences $(22.5 \%$ in urban areas and $9.8 \%$ in rural areas). Sahl (2016) also noted that an assessment of the M\&R initiative showed positive change in capacity development, advocacy, media messaging, campaign and community mobilisation, planning, and coordination (Sahl 2016).

This mixed method study sought to explore how SMCs influence behaviour change and social norm transformation with respect to $\mathrm{FGM} / \mathrm{C}$. It also addressed how existing programmes contribute to, or fit into, a theory of change, as well as assessing the design and implementation of existing SMC programmes in Sudan. The study's specific objectives were to:

- Examine the design and implementation processes of anti-FGM/C SMC initiatives in two states: Khartoum and Gedaref;

- Identify the challenges, promising practices, and lessons learned that emerge during the development and implementation of these initiatives; and

- Assess communities' exposure to FGM/C abandonment messages, their perception of these, and whether these messages have influenced attitudes towards $F G M / C$ abandonment.

\section{Theoretical Underpinnings}

Social norms theory is an important framework for understanding the factors and norms that underpin $\mathrm{FGM} / \mathrm{C}$ practices. $\mathrm{FGM} / \mathrm{C}$ is perpetuated and maintained by a multiplicity of interrelated factors. Understanding these factors is core to the design and implementation of abandonment interventions. Mackie and LeJeune (2009) highlighted three factors that comprise society-level explanations of FGM/C: patriarchy, culture (including ethnicity and religion) and marriageability. They argued that the practice may be attributed to mutual expectations, by men and women, that it is required for marriageability in so far as women and girls' honour-chastity and fidelity-is assured by the practise of $\mathrm{FGM} / \mathrm{C}$. Others have noted that women associate additional connotations with the practise of FGM/C such as cleanliness, beauty, reproduction, and expected fertility (Boddy 1982, Gruenbaum 2001). In Sudan, practising communities also view FGM/C as an Islamic obligation even though there are no religious scriptures that sanction $F G M / C$, and there are many neighbouring Muslim communities that do not practise it. There is the belief that FGM/C may also confer benefits to men. Thus, another reason given by some practising communities is that the practice is related to sexual enjoyment for men, which is a reason for the re-infibulation of women after child birth (Gruenbaum 2001). As a socially sanctioned practice, FGM/C is, therefore, held in place by several social and religious norms in Sudan. Thus, initiatives to formulate abandonment policies and programmes must recognise the significance of FGM/C to not only marriageability but also to the interconnecting issues of social class, ethnicity, and the economic 
and political dynamics of the social context (Gruenbaum 2001) in which practising individuals and communities live.

For decades, many institutions/organisations have implemented FGM/C abandonment interventions using different perspectives to develop behaviour change programmes that target practising communities. The most common abandonment interventions have focused on health risks, sexuality and sexual health, violation of girls and women's rights, and legal approaches (Shell-Duncan 2008, Brown et al 2013). More recently, there has been a shift from focusing on the health hazards and risks to girls and women to addressing the social norms that perpetuate the practice. Such approaches focus on intervening on the social influences that may drive and motivate meaningful behaviour change (Brown et al 2013, Bedri 2012). Within this perspective, the SM approach has gained prominence because it merges two theoretical frameworks that can inform the design of interventions to change social norms. These are social norms theory, which is used to conceptualise the dynamics of behaviour regarding $\mathrm{FGM} / \mathrm{C}$, and SM theory, which informs the design and implementation of interventions that aim at stopping the practice. Social marketing is identified as a programme-planning process to promote voluntary behaviour change (Grier and Bryant 2005). Lee and Kotler (2011) further define it as 'a process that applies marketing principles and techniques to create, communicate and deliver value to influence target audience behaviours that benefit society (public health, safety, the environment and communities) as well as the target audience'.

Hornik and Yanovitsky (2003) argue that the application of the SM approach and the design of SMCs for social change is useful for deeply rooted and culturally embedded practices, such as FGM/C. They note that it is important to have a theory of change to guide the choice of variables to measure/change and the attribution of outcomes to the intervention. The use of theory also helps programme managers understand the groups or individuals for whom a behaviour change intervention is intended. In the SM approach, the latter entails the important step of segmentation-identifying groups at three levels-upstream, midstream, and downstream (Kotler et al 2013). The individuals/groups at midstream are identified as the reference groups and are the influencers who act as a medium of communication between SM projects and the individuals engaged in the 'action' to be changed (i.e., individuals/groups who are downstream). These influencers include peers, friends, relatives, acquaintances, and role models who might bring a positive influence to bear on an individual or group (Andreasen 2005, cited in Kotler et al 2013). The upstream groups, including policy makers, legal institutions, the media, and local leaders, may either support or oppose the practice. Segmentation enables the programme to understand the needs, wants, perceptions, and present behaviour patterns of the target community before acting. It also enables the programme to discern the decision processes that lead to specific behaviours, which may be informed by the options people have, the culture, the value drivers that will permit a change of behaviour, and the potential supporters for change. Social marketing has a clear focus on behaviour and is behavioural-theory based and informed, drawing mostly on an integrative theory framework (National Social Marketing Center 2009).

Social marketing strategies to affect behavioural change involve four elements-the four "Ps": 1) Product, anything that can be offered to a market to satisfy a want or need; in SM, major product elements include the core benefit of behaviour, goods or services a marketer promotes for adoption, and additional product elements to assist behaviour adoption, 2) Price, the cost the target market associates with adopting the desired behaviour; these costs can be tangible (e.g., monetary) or intangible (e.g., social sanctions), 3) Place, where and when the target market will perform the desired behaviour, acquire any related tangible objects, and receive any associated services, and 4) Promotion, persuasive communications designed and delivered to inspire the target audience to action; social marketers determine the messages, messengers, creative strategies, and communication channels to be used. Additional "Ps" have been added to the 
original four "Ps" to align SM application with social phenomena such as FGM/C (Bridges and Farland 2003): 5) Policy formulation, which denotes the critical need for supportive policies, 6) Partnerships, which denote the multiple actors who often need to be engaged for SMC programmes to be successful, and 7) Purse strings, which denote the critical need for funding for the development of SMCs.

For programmes aimed at reducing FGM/C, product refers to abandonment and it is supported by augmented products such as messages sent through mass media, drama, songs, training, and community awareness raising, among others. Price refers to the costs and risks associated with FGM/C practice that are borne by individuals and communities. These costs include health, psychological, social (e.g., stigma and loss of status), and economical (e.g., non-marriageability) costs. In Sudan, for example, the overall contextual features suggest that the costs of abandonment are considerable due to the high possibility of negative social sanctions (Mackie et al 2015). Any campaign aimed at changing behaviours must therefore address these costs. Place or location is an important element of anti-FGM/C SMCs because the venues where messages and products are delivered, such as health facilities, workplaces, and virtual spaces, must be relevant and accessible to the target groups. Coverage and outreach are important considerations in ensuring that adequate numbers of people are reached for a critical mass for change to be achieved. Promotion is an integral core activity that facilitates the link with the target segment of the community. Partnerships offer collective efforts, allow for interdisciplinary and holistic approaches to design, and implement effective interventions given the multiple actors involved in FGM/C abandonment interventions such as government institutions, UN agencies, women and youth groups, and professional associations. Purse strings—or the levels of funding available-is critical. Funding for FGM/C abandonment programmes in Sudan is mainly provided by the UN and international agencies, with modest local contribution. Finally, policies enacted on a behaviour serve to strengthen or weaken it. In the case of $F G M / C$, within the Sudanese context, there are limited policies that support the abandonment of FGM/C.

Social marketing incorporates an "exchange" analysis to understand what an individual has to give up to recoup the benefits from the proposed behaviour (Grier and Bryant 2003). With FGM/C, the proposed behaviour is abandonment of the practice. This concept of exchange is exemplified by the calculations of cost and benefit for change of behaviour, towards abandonment. The SM approach utilises a "competition" analysis to identify what other programmes deliver products and messages and compete for intended audiences' time and attention (Grier and Bryant 2005, National Centre for Social Marketing 2009). With the number and diversity of actors conducting FGM/C abandonment programmes and interventions, competition analysis has great significance.

While many abandonment programmes incorporate SM features, not all programmes can be classified as SMCs. To be labelled as SMC, a programme must:

- Apply marketing concepts and technologies, in particular the four "Ps" must guide all programme activities. However, some scholars (e.g., Lefebvre 2013) argue that '...any marketing element in a programme, whether it starts with a ' $P$ ' or not, needs to be modifiable ....to fit with the priority group' (Lefebvre 2013).

- Have the influencing of voluntary behaviour change as its bottom line. Behaviour change can be conceptualised differently depending on the theory of change that suits the situation best in terms of the target groups, context, and components of the programme.

- Primarily seek to benefit the individuals and their communities not the marketing organisation itself (Andreasen 1994).

Andreasen (1994) provides a checklist of best-practices in SM. One of the core elements of the checklist is that managers should understand the target audience's needs, wants, perceptions, 
and present behaviour patterns before acting. Formative research is one way to better understand the target audience and pre-test designed activities to match the needs. Audience segmentation is considered to ensure communications target specific groups of people who share particular characteristics, understanding, lifestyles, interests, needs, motivations, and barriers (Andreasen 1994, Australian Aid Initiative 2016). Theoretical frameworks to guide audience segmentation consider segmentation of target groups based on cultural and demographic notions, and the stages or status of individuals reached with programmes. These frameworks include social convention theory (Mackie et al 2009), diffusion of innovation theory (Rogers 1995), and stages of change framework (Shell-Duncan 2010).

According to Andreasen, programme managers must also understand the decision process that leads people to adopt the target behaviour. To adopt the behaviour, the target audience must:

1) Be aware and knowledgeable about the options;

2) Embrace the culture and values that permit the behaviour to be considered for adoption;

3) Perceive the behaviour as potentially relevant to contextual aspects and their circumstances;

4) Conclude that the positive consequences of the behaviour exceed the negative consequences to a degree that is superior to realistic alternatives;

5) Believe they can carry out the action; and

6) Believe that others who are important to them will support their action.

Strategies designed to affect behavioural change comprise all four elements of the marketing mix (the four Ps) and may add more Ps that have been used to conceptualise an additional set of strategies applied. Box 1 summarises key steps for designing an SM message.

To understand how SM approaches have worked in Sudan and how people are influenced to consider abandonment, we draw on Mackie and LeJeune's (2009) social convention theory, Roger's (2003) diffusion of innovation theory, and the stages of change theory (Shell-Duncan, 2010). Mackie and LeJeune's (2009) social convention theory suggests that the actions of individuals are achieved through organised diffusion; in other words, individuals spread information, persuade, and debate through existing familial and social networks to promote commitment to FGM/C abandonment. Accordingly, it is argued, that an entire community need not be persuaded to affect social change. Rather, what is required is a motivated "critical mass" of people to collectively decide that they are willing to abandon the practice. A 'critical mass' of families within a community must, publicly, renounce the practice before individual families will believe it is acceptable and non-detrimental to their status not to cut their daughters. When a 'critical mass' of families conform to norm change it is a guarantee that in the case of abandoners, their daughters will not be at risk of social sanctions by the community. This 'critical mass' needs to persuade others (and become the reference group to their network members) to commit to the idea until there are enough (at the tipping point) to act together to make a public commitment to abandon the practice (Mackie and LeJeune 2009). 
Step 1: Understand commercial marketing. The role of commercial marketing in social marketing cannot be overlooked, yet it often is. It is called social marketing because as a discipline it brings the lessons of commercial marketing to a social task.

Step 2: Define the issue. Explain clearly the main behaviour the campaign intends to influence. What is the top priority for action?

Step 3: Understand your audience. To succeed as a marketer - to sell your product/idea - you must understand your audience, their hopes, their dreams, their fears, and their beliefs. Remember, humans are not always rational, and providing rational reasons for behaviour change will not always succeed.

Step 4: Understand the situation/context. Individuals and groups do not live in a vacuum; many factors are at work and may operate to facilitate or hinder what you intend to accomplish.

Step 5: Segment your audience. Research tells us that targeting specific segments of the population with materials tailored to their unique needs, motivations, and experiences will have the greatest impact.

Step 6: Work with others. No single person or organisation has all the skills and knowledge to plan, develop, and deliver social marketing materials.

Step 7: Outline your behavioural goals.

Step 8: Choose your communication channels. It is likely that your target audience receives and engages with information in several ways.

Step 9: Develop strategies and communication messages.

Step 10: Prepare an action plan.

Step 11: Seek feedback, pre-test, and adjust. Obtain feedback from stakeholders and some members of your target audience.

Step 12: Deliver and monitor. Your strategies and communication materials are now reaching your target audience and, you hope, having a positive influence on their behaviour.

Step 13: Measure impact and make adjustments. You have reached the final stage in which, having implemented your strategies and delivered your communication materials according to your action plan, you learn whether what you did had an impact.

Source: (The Australian Initiative; Andersen 1994; Bridges and Farland 2003).

Rogers' (2003) theory of diffusion of innovation offers additional theoretical insight into the mechanisms by which one might create and sustain change at a community level. There are different forms of adaptation, specifically with $\mathrm{FGM} / \mathrm{C}$, because supporters of the practice are likely to resist calls for abandonment. The theory describes the elements that influence the spread of new or innovative ideas, products, or practices to individuals/groups and the characteristics of the individuals or groups that adopt an innovation. An important element of this theory is the innovation-decision process, of five stages: 1) knowledge, when the individual is exposed to the innovation's existence and gains an understanding of how it functions, 2) persuasion, when the individual forms a favourable or unfavourable attitude toward the innovation, 3) decision, when the individual engages in activities that lead to a choice to adopt or reject the innovation, 4) implementation, when the individual puts an innovation into use, and 5) confirmation, when the individual seeks reinforcement for an innovation-decision already made but may reverse the decision if exposed to conflicting messages about it (Rogers 2003). Adopters of an innovation are classified as innovators, early adopters, early majority, later majority, and laggards, depending on their level of uptake of an innovation. Although most of Rogers' work is about individual change, he recently started to consider interactive innovations that consider the interdependence of human behaviour, such as FGM/C, in line with Mackie et al (2015). This implies that some human behaviours are influenced by the interactions between individuals within a specific social system (Rogers 2003, Mackie et al 2015). With FGM/C, resistance to, or the abandonment of, the practice may be understood as the innovative behaviour. We might describe the people identified as 
'critical mass' (Mackie and LeJeune 2009) as innovators and early adopters. The SM approach would then seek to determine the characteristics and motivations for discontinuing FGM/C that typify innovators and early adopters and how such families may be identified and supported (Brown et al 2013).

The stages of change model has been applied in SM programmes since the early 1990s (Andreasen 1994, Lefebvre 2012). Although the model focuses on individual change, it provides useful insights on the segmentation of target groups and the selection of suitable approaches of SM. Shell-Duncan and Herniund (2006) applied this model to create five typologies based on individual's readiness to abandon the practice; that is, willing adherent (thinks FGM/C should continue and adheres to the practice), reluctant adherent (thinks FGM/C should stop but adheres to the practice), contemplator (is undecided both in terms of whether the practice should continue and adherence to the practice), reluctant abandoner (thinks FGM/C should continue but does not adhere to the practice) and willing abandoner (thinks FGM/C should stop and does not adhere to the practice). Prochaska et al (1994) and Brown-Peterside et al (2005) highlight the possibility of relapse of behaviour due to the influence of different types of interventions and note that the best intervention will be the one that best matches the individual's current stage of change.

\section{Conceptualising the Study}

Based on the theories outlined, we conceptualised abandonment as a process that is shaped and influenced by various contextual factors including the political, legal, economic, social, and cultural dynamics at the international, national, and local levels. Thus, we assessed whether the design and implementation processes of SMCs considered the number and diversity of actors and interventions developed and implemented in communities and how they shape the individual process of behaviour change. We also examined whether the SMC interventions were guided by a theory of change and considered the key elements of SMCs. Further, SMCs aim to promote FGM/C abandonment as a new desired norm leading to behaviour change towards FGM/C that is achieved through diffusion (Rogers 2003) of abandonment messages. Thus, we examined the community members' perceptions about the products and messages delivered to them by the SMC interventions and how they think their current situation and attitude towards FGM/C may be attributed to the SMCs interventions.

\section{Methods}

\section{Study Design and Data Collection Methods}

The study used a cross-sectional design with mixed qualitative (key informant interviews [KIls], indepth interviews [IDIs], and focus group discussions [FGDs]) and quantitative (household surveys and observations) methods. The use of mixed methods allowed for richer in-depth exploration of the design and implementation processes of SMCs and assessment of how target audiences perceive SMCs and their perceptions about the influence of SM messages and sources of abandonment decisions.

\section{Study Sites}

The study was conducted in two purposively selected states, Khartoum and Gedaref, that host a diverse group of actors involved in FGM/C abandonment interventions. Sudan's capital city, Khartoum, is situated in Khartoum State. The high population diversity in the state allows for the inclusion of a significant spectrum of social groups. In addition, the majority of SMCs were first initiated, tested, and applied in the state. Geographically, Khartoum State is divided into three clusters that are administratively subdivided into localities; Khartoum and Jabel Awleya in the first cluster, Khartoum North and Nile East in the second, and Omdurman, Umbadda, and Karari in 
the third. One locality from each cluster (a total of three localities) was purposively selected based on the application of SMCs: Sharg Elneil/Hay Al Baraka, Jabal Awlya/Al Kalakla, Umbadda/Alameer Wasat.

Gedaref state is located in eastern Sudan and is historically known for its large mechanised agriculture schemes, which have attracted migrants from different ethnic groups from all over Sudan. As such, the population is culturally and socially diverse. Some migrant ethnic groups are not supportive of $F G M / C$ and thus differ from the indigenous eastern tribes who value the practice. Gedaref State was selected because of the diverse group of actors in the state that work on FGM/C abandonment using a variety of intervention approaches. The Gedaref State Child Welfare Council is also very active and led the enactment and approval of the law that criminalised FGM/C within the state. After the introduction of the Saleema and M\&R campaigns (in 2008 and 2012, respectively), more community-based organisations (CBOs) and community leaders began to be engaged in the implementation of these SMCs. Two localities were selected in Gedaref: one in the centre of the state-Gedaref/Wasat, and another in the rural areas-Al Faw.

\section{Study Population}

The study population comprised representatives from different organisations that were involved in the design and implementation of SMCs, donor organisations, and the wider community in areas where anti-FGM/C interventions have been implemented. Organisations involved in the design and implementation of SMCs included the government, United Nations (UN) agencies, universities, national NGOs, and CBOs. Most participants from government institutions participated in the design process of interventions and oversaw the implementation of the interventions conducted by partners. Governmental institutions were also responsible for the legal aspects and in policy formulation in line with the broader strategic commitments of the government. A few, such as the National Council for Child Welfare in Gedaref State, were also involved in the implementation of interventions. UN agencies, such as UNICEF and UNFPA, and WHO provided technical and financial support to partners engaged in SMCs, while other donors provided funds for their partners who designed and/or implemented the campaigns. National NGOs and CBOs were mostly engaged in the implementation process and advocacy. Some of the more experienced organisations assumed both functions of design and implementation. Other bodies, such as universities and research centres, were primarily engaged in research, training, and capacity building for national institutions; only the College of Community Development at Gedaref University was engaged in the implementation of SMCs in collaboration with local CBOs. All organisational representatives were core staff in their respective institutions. The institutions were diverse in type, mandate, and scope of engagement.

At the community level, the study population comprised participants in small groups targeted by "customised" products and activities such as training, seminars, public talks, and 'born Saleema' activities (in the case of the Saleema campaign); the general population who were reached by broader public communication messages and products were also included.

\section{Sampling Strategy}

For the qualitative individual interviews, participants were purposively selected from the institutions involved in the design and implementation of SMCs in the two research sites or from the specific target groups reached with customised products of the SMCs. For the FGDs with community members, the selection of individuals was guided by field coordinators from the targeted communities to ensure adequate representation of participants based on key demographic variables relevant to the objectives of the study.

Participants for the quantitative survey were selected using a multistage cluster sampling technique. Within each state, the selection of the localities was based on the implementation of 
SMCs (including Saleema and M\&R). In each locality, one administrative unit was purposively selected. In each administrative unit, households were selected using a systematic random sample with intervals based on the geographical mapping of the targeted part of the administrative unit (residential blocks). With guidance from field coordinators who were familiar with the areas, households were selected based on whether parents were residing with adult sons and daughters. The reason for selecting such households was to allow for representation of the different generations as per the inclusion criteria and to assess how different generations perceive and respond to SMCs.

A total of 724 participants in both states completed the quantitative survey. Survey respondents' socio-demographic characteristics are summarised in Table 2 (following page). In both states, the majority of participants were ages 21 to 40 years. Fewer than 10 percent of participants were younger than 20 years. The majority of participants had either primary or secondary education. A quarter of men (25\%) in Khartoum and Gedaref were university graduates, while two percent had post-graduate education. Fifteen percent and 13 percent of female participants in Al Faw and Khartoum, respectively, had not attended school. Less than five percent of men in both states had not attended school. Most of the participants were self-employed: 45 percent in Al Faw, 43 percent in Gedaref, and 44 percent in Khartoum. Thirty-three percent of men in Khartoum reported administrative or other professional occupations. Overall, however, few participants reported professional or administrative occupations. The majority of women were housewives: 67 percent in Al Faw, 74 percent in Gedaref and 74 percent in Khartoum. The majority of respondents perceived themselves to be in the mid-level income group (based on the minimum wage level). Most of the respondents live in households inhabited by six to 10 persons; 51 percent of males and 48 percent of females in Al Faw, 58 percent of males and 54 percent of females in Gedaref, and 59 percent of males and 55 percent of females in Khartoum. Considering the high fertility rate in Sudan and the possibility that many households include members of the extended family, the large numbers of people in households are expected.

Table 2. Quantitative survey respondents' sociodemographic characteristics, by site and sex

\begin{tabular}{|c|c|c|c|c|c|c|c|c|c|c|c|c|}
\hline & \multicolumn{4}{|c|}{ Al Faw } & \multicolumn{4}{|c|}{ Gedaref } & \multicolumn{4}{|c|}{ Khartoum } \\
\hline & \multicolumn{2}{|c|}{ Male $(n=97)$} & \multicolumn{2}{|c|}{ Female $(n=86)$} & \multicolumn{2}{|c|}{ Male $(n=94)$} & \multicolumn{2}{|c|}{ Female $(n=93)$} & \multicolumn{2}{|c|}{ Male $(n=175)$} & \multicolumn{2}{|c|}{ Female $(n=179)$} \\
\hline & $n$ & $\%$ & $\mathrm{n}$ & $\%$ & $\mathrm{n}$ & $\%$ & $\mathrm{n}$ & $\%$ & $\mathrm{n}$ & $\%$ & $n$ & $\%$ \\
\hline \multicolumn{13}{|l|}{ Age } \\
\hline$\leq 20$ years & 3 & 3 & 4 & 4 & 8 & 8 & 6 & 7 & 10 & 6 & 10 & 5 \\
\hline $21-30$ years & 25 & 27 & 27 & 32 & 26 & 28 & 35 & 38 & 58 & 33 & 62 & 35 \\
\hline $31-40$ years & 23 & 24 & 32 & 38 & 18 & 19 & 33 & 36 & 40 & 23 & 60 & 33 \\
\hline $41-50$ years & 22 & 23 & 17 & 20 & 24 & 26 & 14 & 15 & 31 & 18 & 31 & 17 \\
\hline$>50$ years & 22 & 23 & 5 & 6 & 18 & 19 & 4 & 4 & 36 & 20 & 16 & 10 \\
\hline \multicolumn{13}{|l|}{ Education } \\
\hline No education & 3 & 3 & 13 & 15 & 3 & 3 & 6 & 6 & 7 & 4 & 24 & 13 \\
\hline Khalwa & 1 & 1 & 2 & 2 & 10 & 11 & 1 & 1 & 9 & 5 & 11 & 6 \\
\hline Primary & 38 & 39 & 30 & 35 & 27 & 29 & 37 & 40 & 46 & 27 & 46 & 26 \\
\hline Secondary & 35 & 36 & 23 & 27 & 27 & 29 & 33 & 36 & 60 & 35 & 51 & 29 \\
\hline University & 17 & 18 & 18 & 21 & 24 & 25 & 14 & 15 & 43 & 25 & 41 & 23 \\
\hline Post Graduate & 1 & 1 & 0 & 0 & 2 & 2 & 1 & 1 & 6 & 3 & 4 & 2 \\
\hline Other & 2 & 2 & 0 & 0 & 1 & 1 & 1 & 1 & 2 & 1 & 2 & 1 \\
\hline \multicolumn{13}{|l|}{ Occupation } \\
\hline Administrator & 5 & 5 & 1 & 1 & 4 & 4 & 4 & 4 & 13 & 7 & 4 & 2 \\
\hline Professional & 20 & 21 & 9 & 11 & 18 & 19 & 7 & 8 & 46 & 26 & 10 & 5 \\
\hline Farmer/Herder & 11 & 11 & 0 & 0 & 7 & 7 & 2 & 2 & 0 & 0 & 3 & 2 \\
\hline House Wife & 0 & 0 & 58 & 67 & 0 & 0 & 69 & 74 & 0 & 0 & 133 & 74 \\
\hline Self-Employed & 43 & 45 & 5 & 6 & 40 & 43 & 2 & 2 & 77 & 44 & 5 & 3 \\
\hline Student & 14 & 14 & 7 & 8 & 23 & 25 & 7 & 8 & 28 & 16 & 19 & 11 \\
\hline Unemployed & 4 & 4 & 6 & 7 & 2 & 2 & 2 & 2 & 10 & 6 & 5 & 3 \\
\hline
\end{tabular}




\begin{tabular}{|c|c|c|c|c|c|c|c|c|c|c|c|c|}
\hline & \multicolumn{4}{|c|}{ Al Faw } & \multicolumn{4}{|c|}{ Gedaref } & \multicolumn{4}{|c|}{ Khartoum } \\
\hline & \multicolumn{2}{|c|}{ Male $(n=97)$} & \multicolumn{2}{|c|}{ Female $(n=86)$} & \multicolumn{2}{|c|}{ Male $(n=94)$} & \multicolumn{2}{|c|}{ Female $(n=93)$} & \multicolumn{2}{|c|}{ Male $(n=175)$} & \multicolumn{2}{|c|}{ Female $(n=179)$} \\
\hline & $\mathrm{n}$ & $\%$ & $n$ & $\%$ & $\mathrm{n}$ & $\%$ & $n$ & $\%$ & $n$ & $\%$ & $\mathrm{n}$ & $\%$ \\
\hline Other & 0 & 0 & 0 & 0 & 0 & 0 & 0 & 0 & 1 & 1 & 0 & 0 \\
\hline Income level & & & & & & & & & & & & \\
\hline Very high & 0 & 0 & 0 & 0 & 0 & 0 & 1 & 1 & 0 & 0 & 0 & 0 \\
\hline High & 4 & 4 & 1 & 1 & 2 & 2 & 2 & 2 & 5 & 3 & 8 & 5 \\
\hline Middle & 72 & 74 & 73 & 85 & 71 & 76 & 76 & 82 & 119 & 68 & 153 & 85 \\
\hline Low & 17 & 18 & 10 & 12 & 15 & 16 & 12 & 13 & 43 & 25 & 14 & 8 \\
\hline Very Low & 4 & 4 & 2 & 2 & 6 & 6 & 2 & 2 & 8 & 4 & 4 & 2 \\
\hline Migration & & & & & & & & & & & & \\
\hline $\begin{array}{l}\text { Resident since } \\
\text { birth }\end{array}$ & 87 & 90 & 72 & 85 & 69 & 73 & 48 & 53 & 120 & 69 & 130 & 73 \\
\hline Migrant & 10 & 10 & 13 & 15 & 25 & 27 & 43 & 47 & 55 & 31 & 49 & 27 \\
\hline Household size' & & & & & & & & & & & & \\
\hline $1-5$ & 29 & 30 & 20 & 23 & 20 & 21 & 24 & 26 & 46 & 26 & 37 & 21 \\
\hline $6-10$ & 49 & 51 & 41 & 48 & 54 & 58 & 50 & 54 & 102 & 59 & 99 & 55 \\
\hline $11-15$ & 17 & 18 & 22 & 26 & 14 & 15 & 15 & 16 & 22 & 13 & 39 & 22 \\
\hline$>15$ & 1 & 1 & 3 & 3 & 6 & 6 & 4 & 4 & 4 & 2 & 4 & 2 \\
\hline
\end{tabular}

Note: Frequencies may not add up due to missing values

\section{Data Collection Instruments}

Data collectors used semi-structured interview guides for the FGDs and individual interviews. Observations were conducted by data collectors and the research team. Quantitative survey data were collected using an interviewer-administered questionnaire. The questionnaire was prepared in English and translated into colloquial Arabic for relevancy and ease of administration by data collectors. The questionnaire was then pre-tested in Khartoum State, Umbadda locality, under the supervision of a researcher from the study team. The questionnaire was then amended based on feedback from the pre-test.

\section{Data Collection Process}

Data were collected between November 2016 and March 2017 by a team of trained data collectors. The data collectors' training covered field work procedures as well as a review of the study tools. The training also highlighted issues related to the study sites in terms of their characteristics, cultural and social aspects, and orientations on how to deal with any contingencies that may arise. Roles and responsibilities of the whole team (including data collectors, field coordinators, community facilitators, and the study team members) were clarified.

The data collection process began with qualitative KIls in Khartoum State. Participants for the KIls were identified by representatives from the targeted organisations who had previous connections with Ahfad University for Women (AUW) and the Gender and Reproductive Health and Rights Resource Centre (GRACe). A total of $22 \mathrm{KIls}$ were conducted with top level officials who were closely engaged in the design and/or implementation of interventions for FGM/C abandonment within their targeted institutions/organisations, or offering expertise, technical support, and funds as in the case of UN agencies. The interviews were conducted by the study team members ( $\mathrm{PI}$, co-PI, senior researcher). The data from the interviews were recorded in field notes which were then transcribed directly into English in preparation for analysis. Following the KIls, the data collectors conducted IDIs with individuals who were targeted by customised services such as trainings, direct talks, public speeches, and 'Born Saleema' activities. Nine interviews were conducted with both men and women in this group. FGDs with selected individuals ( $n \sim 56)$ from the public in each locality were also utilised to add more depth on the perception of people on FGM/C. Eight FGDs were conducted (4 with men, 4 with women). 
The quantitative surveys were conducted following the qualitative interviews. Data collection began with the mapping of the sites to identify the sample households. The field coordinators and community facilitators, who were familiar with the sites, acted as entry points to community leaders and officials. All data collectors were trained to observe any features that would enrich the collected data such as campaign materials (e.g., posters, banners, and adverts for public activities). For quality assurance, the coordinators conducted daily data checks under the study team supervision.

\section{Data Management and Analysis}

The qualitative interviews were transcribed into English. Code labels were then created guided by relevant literature and derived from the interviews, anecdotes and refined by the researchers. The creation of code labels was followed by writing 'memos' for identified categories from the codes and emerging themes (Strauss and Corbin 1990, Grbich 2013). The qualitative data findings and results are presented in the form of narrative text following the identified themes and categories, and guided by the research objectives and questions.

Quantitative data analyses were conducted using SPSS software. Prior to analysis, data were cleaned. Univariate and bivariate statistics were computed to summarise the channels through which survey respondents accessed FGM/C information, content of messages, frequency of exposure to messages, attributes that enhance the trustworthiness of messages, consultation with reference groups, and the decision reached on $\mathrm{FGM} / \mathrm{C}$ abandonment. The quantitative results are presented in the form of tables and figures summarising data that fulfil the objectives and answer questions pertinent to the perceptions of members from the community at large on FGM/C abandonment. Results are presented separately for Khartoum and the two sites in Gedaref (Gedaref and Al Faw). Both data sets, quantitative and qualitative, are integrated and interpreted.

\section{Ethical Considerations}

Ethical approval for the study was granted by the Population Council's Institutional Review Board and by the Research and Grant Unit at AUW. Prior to data collection, the study team obtained official authorisation letters to enter the study sites. All members of the research team who were involved in the research received training on ethical issues. Study participants were informed about the study before signing the consent forms. All participants provided written consent prior to the interviews. To enhance the confidentiality of information gathered from study participants, all interviews were conducted in secure spaces providing auditory privacy, personal identifiers were removed from all study materials, and participants in FGDs were requested to verbally commit to maintaining confidentiality.

\section{Findings}

This section summarises the study's key findings. The first section highlights the findings from the interviews with representatives of selected institutions/organisations engaged in the design and implementation of interventions and focuses on the design and implementation processes of antiFGM/C SMC initiatives in the two states. The second section summarises best practices, challenges and lessons learned during the development and implementation of these initiatives. The final section documents the results of the quantitative survey that assessed community perceptions about the reach, appropriateness, and impacts of the SMCs. 


\section{Design and Implementation of Social Marketing Campaigns for FGM/C Abandonment}

The study sought to understand the processes that guide the design and implementation of SMCs for FGM/C abandonment and to investigate whether those who design and implement FGM/C abandonment interventions adhere to SM principles and guides.

The interviews revealed that a variety of interventions to end FGM/C had been designed and implemented by diverse actors (designers and implementers) from as early as the 1970s. However, SMCs were a recent introduction. As illustrated in the following quotes from key informants working with governmental institutions, the key rationale for designing SMCs was the perceived inadequacy of previous approaches and the need for more positive approaches/messages to change social norms:

'Past approaches using negative messages do not help abandoners to defend themselves and their daughters and protect their rights. Saleema was designed to challenge and change the negative norms such as using the negative term 'Ghalfa' [negative connotations] to describe uncut girls'.

'Before the Saleema approach we used to work using a health approach that informed [people] about the health harms of FGM/C practice. We also worked in another campaign related to FGM/C specifically targeting women's perception of the link between cleanliness and FGM/C. We conducted research on FGM/C with 10 groups of women age 20 to 60 years. Then prepared a brochure with messages from results of the research; pre-tested the messages and now the brochure is distributed in all health facilities in the state'.

\section{Use of Theory and Alignment with Andreasen's (1994) Checklist of Best Practices in Social Marketing}

Effective interventions are underpinned by an appropriate theoretical framework to guide design and implementation, and so participants were asked about the theoretical perspectives underpinning the processes of design and implementation of SMCs. With the exception of the Saleema initiative, which is highly sophisticated and applies several theories explained during the trainings by the programme, most government and NGOs and institutions revealed that they initiated, designed, and implemented interventions in accordance with their organisation's mandate and mission, rather than drawing on a theoretical perspective or a theory of change. One key informant from an implementing governmental organisation noted that the basic principles guiding the interventions stemmed from a child's rights perspective, supported by international and regional conventions. According to the informant, the institution's activities were driven by the need to protect children's rights, the child's best interests, and child development without an explicit reference to a theory of change:

'The Council follows a strategy for FGM/C abandonment in a decade 2008 to 2018 which aspires for great norm change; however, we don't explicitly mention reference to a theory of change per se'.

In contrast, representatives from UN agencies noted that their FGM/C abandonment initiatives were underpinned by a theory of change. Emphasising that institution-led FGM/C abandonment interventions were informed by theory, one key informant from a UN agency noted:

'We use the theory of 'diffusion of innovation' and a perspective based on freedom from discrimination, equal rights, full participation, and sustainable human development for FGM/C abandonment'. 
Specifically, examining the design of both Saleema and M\&R campaigns, the study found that most key informants' descriptions of the design processes for both campaigns did not make explicit reference to the use of theory. However, the design of both campaigns accounted for key aspects of an SM approach and implicitly addressed some of the major elements of the marketing mix. In line with Andreasen's (1994) checklist of best-practices in SM, for example, both campaigns began with formative work to understand the target audience and to pre-test designed ideas. For example, the design of the M\&R campaign was reportedly informed by social surveys that provided basic information necessary for the understanding of the initial idea and the dynamics that influence further development of the activities. Similarly, for Saleema, the developers organised a consultative workshop that brought together relevant actors from different states, the NCCW, the $\mathrm{UN}$, and some NGOs and CBOs to discuss the messaging for the campaign. As illustrated in the following quotation from a representative from a UN agency, the workshop was important in ensuring wider participation in the design of the campaign:

'The consultation on Saleema ensured participation of communities from all states in all stages. Saleema social marketing is not only visibility but marketing of positive ideas. The process of consultation came out with a ground message, "Every girl is born Saleema". The action message for that is "let every girl grow Saleema"'.

The role of partnerships, one of the additional "Ps" in the adapted marketing mix, was also highlighted. Key informants in the M\&R campaign noted that institutions had established partnerships with the Ministry of Guidance and Endowment (MoGE), Ministry of Welfare and Social Security (MoWSS), Consortium of Violence Against Women (C/VAW), NCCW, Federal Ministry of Health $(\mathrm{FMoH})$, and $\mathrm{AUW}$. This consortium of stakeholders with different expertise was perceived to ensure widespread support for the campaign. The importance of partnerships was also highlighted in the following quotes:

'Before starting the implementation, we usually identify the NGOs and CBOs with whom we collaborate to get the work done'. Key informant, implementing organisation

'At community level, we have partnerships with the General Sudanese Women Union, Preschool Education Directorate, Council of Guidance and Sufi sects who deliver some of our activities'.

Key informant, implementing organisation

Although NGOs are reported to implement interventions in collaboration with partners from different community groups (CBOs, Youth and Women Groups), line ministries, and other governmental agencies, some organisations with extensive experience in the field tended to work autonomously. This point is illustrated in the following quote from a key informant from an NGO:

'We usually work in close collaboration with other institutions and the community... however, we implement some activities relying on our own expertise and resources'.

As noted, a key aspect of the SM approach is the segmentation of target audiences to facilitate the design and delivery of messages that are appropriate for the different audiences (Kotler et al 2013). Key informants noted that the selection of target groups was often based on community assessments and involved three levels of segmentation: 1) upstream institutions and individuals who play a significant role in providing support, 2) the public at large, where the segmentation process is guided by demographic attributes; social, cultural diversity, belief and value systems, FGM/C prevalence, and gender equality, among others, 3) smaller and specific groups from the public who include professionals, professional associations, CBOs, and prominent figures such as community leaders, who are usually recruited to conduct certain activities and to serve as influencers, role models and, sometimes, educators. Underscoring the importance of carefully identifying potential influencers, a key informant from an NGO noted: 
'The criteria for recruiting those delivering messages must be carefully set because FGM/C is a sensitive issue. Hence, we require someone who is capable and believes in the message he/she is trying to convey, confident, has good communication skills, a good speaker, has assets of social relationships, and is respected by others'.

Text box 2. Examples of key messages for different audiences

Messages targeting parliamentarians and the public ما اكرمهن الا كريم وما اهانهن الألئي

It is the kind and merciful who respect women...while it is only the evils who can harm women

God has created humans (girls) in the best form

$$
\text { وخلقنا الانسان في احسن تقويم }
$$

لا للختان

$\mathrm{NO}$ to $\mathrm{FGM} / \mathrm{C}$

Examples of messages placed on street banners:

$$
\text { دعو ها آمنة لا تعيقو ها بالختان }
$$

Leave the girl safe, do not hinder/constrain her with FGM/C

It is time to stop $\mathrm{FGM} / \mathrm{C}$

Following the segmentation of audiences, programmes reportedly designed different messages and products for the different groups (Box 2 illustrates messages targeting different audiences). Explaining the importance of appropriate messaging for different groups, one informant from a governmental institution involved in intervention implementation noted, 'the messages that target the parliamentarians are different from those targeting people at community level; as I mentioned, it is based on

the results of community assessment; this contributes to the relevance of products and messages'. Language, literacy, and socio-economic factors were also identified as important considerations when designing messages. This was noted by an informant from an NGO, who explained that messages on $\mathrm{FGM} / \mathrm{C}$ in conservative communities were integrated with messages addressing other harmful traditional practices, such as early marriage. Understanding the target audience's attitudes was also critical to ensure the relevance and acceptance of messages. Ongoing SMCs, such as Saleema, were noted to focus on collective change by means of participatory tools such as community dialogue, public declarations and 'taga' pledge, reaching individuals at "downstream" level, and some groups at midstream level.

Most SMC designers and implementers use similar channels to deliver messages to the target audiences. Considering Place or venues where messages and products are delivered, informants noted that the selection of the delivery channels depended on many aspects including a target group's characteristics and needs, cultural preferences, socio-economic status, infrastructure/ technological capacity, and financial and human resources. For Saleema, the primary channels are reported to be non-print mass media (such as television or radio), interpersonal communications, and printed media.

Multiple methods, such as training with specific and customised manuals, sensitising talks and programmes, were simultaneously used to deliver messages. Community dialogues were noted to be a prominent method used by one of the governmental institutions in Gedaref State. These community dialogues included open discussions and deliberations after talks presented by community leaders, who were mostly Sheiks (religious leaders) in mosques and 'Khalwa' (a religious type of early schooling which sometimes accommodates adult literacy classes). Dialogues also occurred in women's groups, especially in what is known as 'coffee gatherings'. In Western Sudan, 'Hakamat' women-a socially acknowledged group of influential women singersshared messages.

The Saleema SMC also included some innovative elements such as the use of the internet, mobile phone chat rooms, face-to-face dialogue at community level, and the counselling of pregnant women and new mothers. The "Born Saleema" initiative included a hospital-based component that aimed to provide parents with a supportive environment for committing themselves to keeping their 
new-born daughters Saleema for life. With respect to the latter, however, one midwife in one of the hospitals where the initiative was applied, noted that the initiative was no longer being implemented due to the 'limited technical capacity of those who deliver the messages, the issue of time nonsuitability (directly after giving birth) and the relatively high cost of providing this product since it entails provision of some gift packages for the mother and the new-born baby girl'.

Key informants further noted that the timing of the delivery of different types of messages varied depending on the target group. Underscoring this point, one informant from a governmental institution stated:

'Messages that target the public at large through radio are usually repeated several times a day. Posters, especially those on banners in public places are accessible to more people and can be seen more frequently. Theatre shows can target communities once in a while. Advocacy interventions, which target policy and decision makers, tend to be less frequent'.

As noted, Purse strings or funding is critical for effective development and implementation of SMCs. Key informants noted that most FGM/C interventions in Sudan were funded by bilateral donors such as DfID and the Governments of Norway, the Netherlands, and Sweden, as well as by international organisations such as UNICEF, UNFPA, Save the Children, Norwegian Church Aid, and WHO. A few national NGOs were reported to partially fund interventions while the Sudanese government made in-kind contributions including human resources and other tangible facilities. However, as highlighted later, the lack of funding was a critical challenge facing many implementers.

\section{Pre-testing, Monitoring, and Evaluation}

According to Grier and Bryant (2005) the SM process is a continuous and iterative process that begins with initial planning followed by formative research and strategy development. These activities are then followed by the development of the campaign and pre-testing of the interventions prior to implementation. The final task is monitoring and evaluation (M\&E), which they note is critical for identifying issues that need to be addressed as campaigns are being implemented, for assessing campaigns' effectiveness and informing need for continued implementation. This study, therefore, examined whether institutions pre-tested SMC interventions, as well as whether they monitored and evaluated these campaigns.

According to the key informants, all Saleema products and messages were pre-tested prior to the launch of the campaigns. Underscoring this point, one key informant from one of the ministries noted:

'Saleema messages came to us after extensive pre-testing and we have monitoring tools [assessment forms] for the sessions organised by health promoters and for service providers. The forms are filled and submitted monthly by those delivering messages'.

Monitoring and evaluation was also noted to be an integral component of the Saleema campaign and key informants noted an M\&E framework aligned to the various stages of the intervention had been designed for the campaign. The framework outlined 1) the community and context assessment, 2) pre-testing, 3) monitoring of the implementation of activities, and 4) evaluation of results and outcomes. With respect to the latter, a key informant from an implementing governmental institution noted that there was an ongoing evaluation of the campaign that was funded by DfID. Similarly, participants noted that the M\&R campaign also had an M\&E framework.

Although key informants noted that the existing programmes had M\&E frameworks, some working with NGOs noted that they lacked credible evidence to assess the influence of the different messages and products on attitudes and behaviours in the target audiences. One key informant stated: 
'We have no evidence; from observation, we feel religious messages can be considered as the most accepted by people. This is because most people trust religious sources and references. In addition, we believe that the positive messages are influential; they can make a difference. Now we are participating in Saleema M\&E to see how much progress has been achieved'.

Key informants from four NGOs also stated they had not assessed the interventions they were implementing and thus were unable to evaluate the effects of their interventions. Explaining the challenges faced in evaluating their programmes, one key informant noted:

'To identify the most influential approach is not an easy task because their influence may be overlapping, it is not easy to differentiate between approaches because we use many approaches simultaneously'.

\section{Best Practices, Challenges, and Lessons}

In this section we summarise key informants' perceptions about best practices in SMCs, challenges in designing and implementing these campaigns, and key lessons.

\section{Best practices}

Key informants highlighted best practices associated with their campaigns and interventions, including:

- Pre-testing to ensure methods and messages are relevant and customised to meet a community's needs;

- Post-campaign assessments to provide implementers with feedback to improve future methods and messages;

- Training community leaders to deliver messages because they are an influential and trusted group in the community;

- Establishing 'protection groups' (community members selected by implementing NGOs/ CBOs, recognised at community level) to contribute to sustainability of abandonment interventions; and

- Complementary interventions such as the 'safe motherhood fund' and livelihood support in some disadvantaged communities as an entry approach for social norm change. According to the key informants, these complementary interventions empower the community socially and economically and make them more likely to abandon the practice. Similarly, the incorporation of the Saleema logo and positive messages on children's growth and vaccination cards was considered a best practice because it was perceived to promote the new norm of 'Saleema'.

\section{Challenges}

Key informants highlighted design and implementation challenges, such as:

- Limited theoretical and conceptual knowledge to guide application of the SM approach;

- Negative impact of counter campaigns led by non-abandoners and others who advocate for the practice on religious arguments;

- In the case of specific interventions using Saleema messages, some designers and implementers noted that Saleema messages were not clearly linked to FGM/C abandonment;

- Limited utilisation of evidence and knowledge produced around FGM/C issues by different stakeholders; 
- Weak political will in some institutions. For example, some key informants noted the resistance of the Medical Council to issue a code of conduct for health providers related to FGM/C practice;

- Dilution of FGM/C issues when they are integrated into reproductive health and maternal mortality messages and interventions;

- Resistance to change by many targeted groups due to the common perception that FGM/C is a traditional cultural practice;

- Weak or contradictory role played by the media. For example, key informants noted that some media channels transmitted messages supporting the 'Sunna' or Type I cutting, while others highlighted the exclusion of men in FGM/C activities; and

- Limited outreach to communities in remote areas which, in most cases, was attributed to a lack of funding.

\section{Lessons}

Almost all the key informants underscored the importance of pre-campaign assessments to enhance the relevance of the programmes and interventions and to enable the segmentation of target groups in line with the principles of SM. UN agency representatives similarly noted the need for campaigns to be culturally-sensitive, symbolic, and to have connectivity to people. They noted that the training of community leaders directly engaged in delivering Saleema messages to their communities was important. The customisation of SMC products and diversity in methods of delivering messages to target groups were reported to have helped increase access and inclusion. Informants also highlighted the need for post-campaign evaluations, which they considered essential to learning about positive practices and to help address weaknesses in intervention design and implementation. Relevant to that is the importance of good documentation of programme contents and ease of access to documentation as a source of learning.

\section{Community Perceptions of FGM/C Abandonment Interventions}

This section documents the results of the quantitative survey that assessed community perceptions about the reach and exposure, appropriateness, and impacts of the SMCs.

\section{Exposure to SMCs on FGM/C abandonment: Sources and methods of message delivery}

The majority of survey respondents had been exposed to FGM/C abandonment messages through different channels (Figure 2). Over two thirds of respondents had been exposed to these messages through non-print mass media, such as television and radio. In all sites, a lower proportion of females than males had been exposed to FGM/C abandonment messages through non-print mass media. However, the difference in the proportion of females and males exposed to FGM/C abandonment messages through non-print mass media was only statistically significant in Khartoum ( $p=0.026$ ). Except for males in Gedaref, among whom 69 percent had been involved in interpersonal communication about FGM/C abandonment, just over 50 percent of survey respondents in the other sites, had similarly been involved in interpersonal communications about FGM/C abandonment, with no statistical difference in the proportion of females and males in all study sites ( $p=0.438$ in Al Faw, 0.053 in Gedaref, and 0.301 in Khartoum). 
Figure 2. Percentage distribution of survey respondents' exposure to FGM/C abandonment messages via different delivery channels, by site and sex

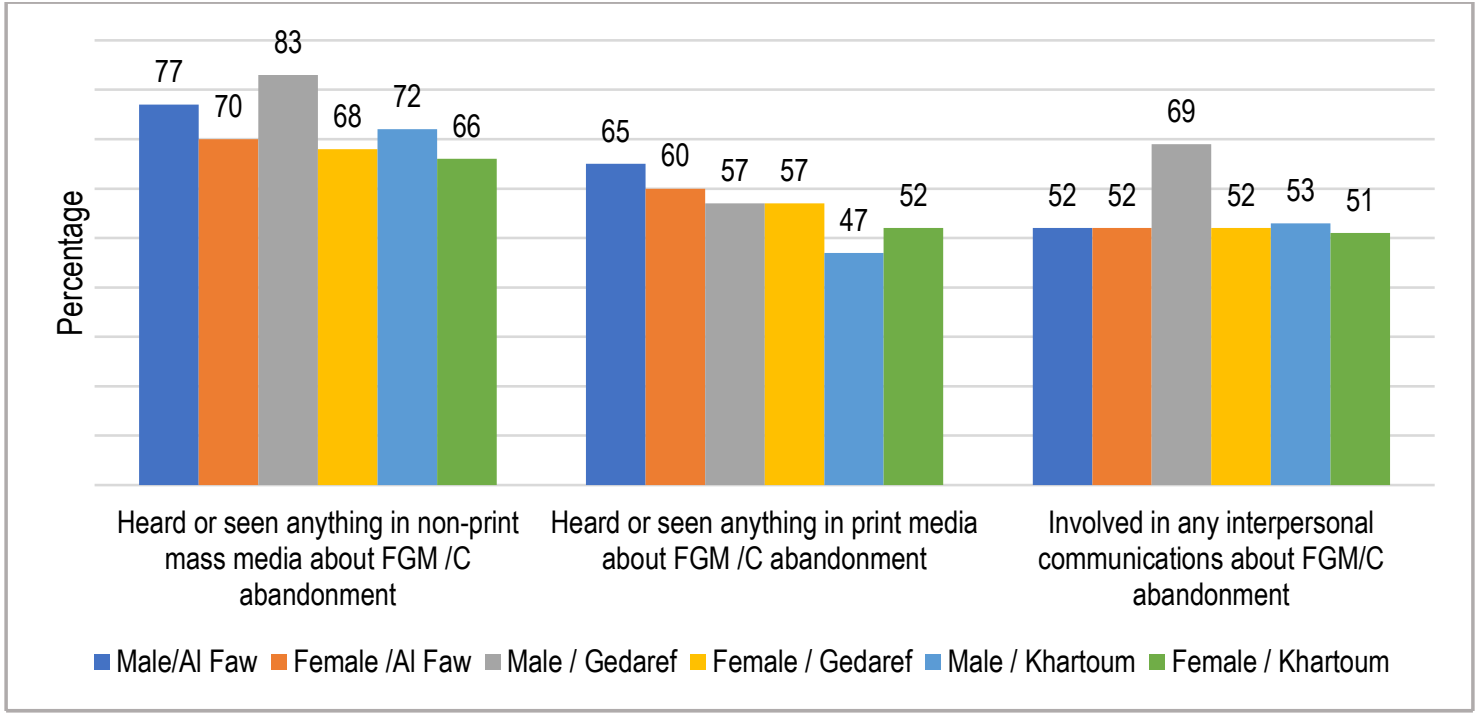

Table 3 (following page) summarises the key findings related to exposure to these messages through non-print mass media (e.g., radio, TV, internet, social media). Over two thirds of male and female respondents had heard or seen messages related to FGM/C through the non-print mass media (Figure 2). Among these respondents, the majority (78\% to $90 \%$ ) had heard or seen these messages on television. The radio was the second most common channel through which FGM/C abandonment messages were received. While in Khartoum 19 percent of men and 12 percent of women exposed to non-print mass media reported that they had seen these messages on social media, fewer than 10 percent of respondents in other sites had heard or seen these messages on social media. The primary modes of delivery via the non-print mass media were talk shows and TV advertisements. In Khartoum, about two thirds of respondents who were exposed to non-print mass media had heard these messages on talk shows. Less than 10 percent of respondents exposed to non-print mass media had heard FGM/C abandonment messages in songs. The proportion of those exposed to these messages through the non-print media who reported that they had heard these messages many times ranged from 55 percent among males in Gedaref to 72 percent among females in the same area. Differences between males and females in Gedaref with respect to exposure to non-print media (method of delivery, frequency of exposure, and content) were statistically significant.

Table 3. Percent distribution of survey respondents' exposure to FGM/C abandonment messages via non-print mass media, by site and sex

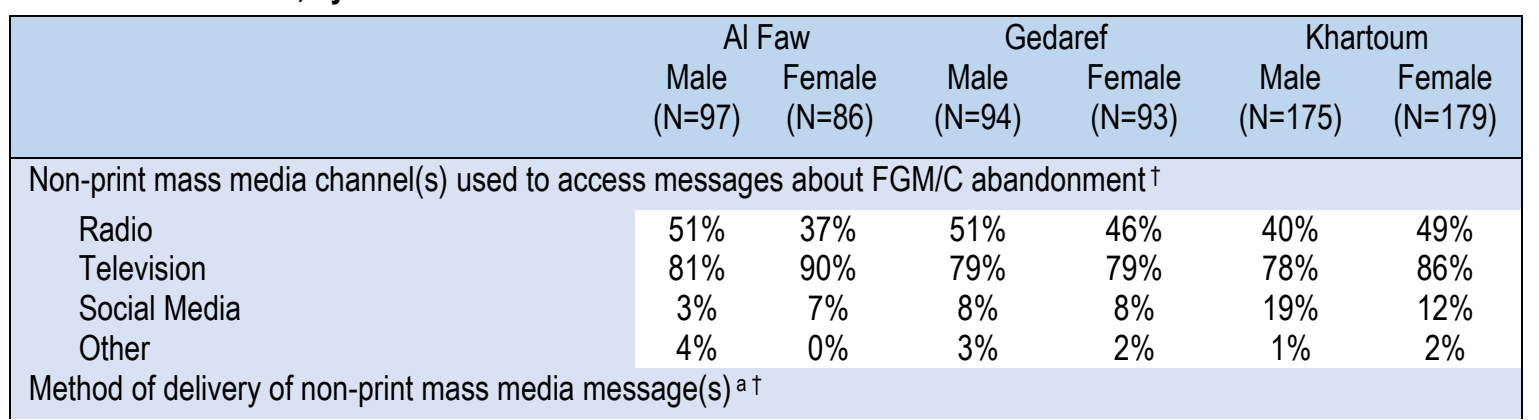




\begin{tabular}{|c|c|c|c|c|c|c|}
\hline & \multicolumn{2}{|c|}{ Al Faw } & \multicolumn{2}{|c|}{ Gedaref } & \multicolumn{2}{|c|}{ Khartoum } \\
\hline & $\begin{array}{l}\text { Male } \\
(\mathrm{N}=97)\end{array}$ & $\begin{array}{l}\text { Female } \\
(\mathrm{N}=86)\end{array}$ & $\begin{array}{c}\text { Male } \\
(\mathrm{N}=94)\end{array}$ & $\begin{array}{l}\text { Female } \\
(\mathrm{N}=93)\end{array}$ & $\begin{array}{c}\text { Male } \\
(\mathrm{N}=175)\end{array}$ & $\begin{array}{l}\text { Female } \\
(\mathrm{N}=179)\end{array}$ \\
\hline Talk show & $37 \%$ & $43 \%$ & $56 \%$ & $27 \%$ & $61 \%$ & $67 \%$ \\
\hline Songs & $8 \%$ & $2 \%$ & $4 \%$ & $8 \%$ & $6 \%$ & $3 \%$ \\
\hline Role play/drama & $19 \%$ & $15 \%$ & $8 \%$ & $16 \%$ & $19 \%$ & $17 \%$ \\
\hline Radio advertisement & $16 \%$ & $5 \%$ & $5 \%$ & $32 \%$ & $6 \%$ & $7 \%$ \\
\hline TV advertisement & $36 \%$ & $32 \%$ & $26 \%$ & $29 \%$ & $49 \%$ & $51 \%$ \\
\hline \multicolumn{7}{|c|}{ Frequency of exposure to non-print mass media messages a $\dagger$} \\
\hline Many times & $65 \%$ & $66 \%$ & $55 \%$ & $72 \%$ & $63 \%$ & $56 \%$ \\
\hline Few times & $33 \%$ & $33 \%$ & $45 \%$ & $28 \%$ & $37 \%$ & $40 \%$ \\
\hline Rarely & $1 \%$ & $2 \%$ & $0 \%$ & $0 \%$ & $1 \%$ & $3 \%$ \\
\hline \multicolumn{7}{|c|}{ Content of the accessed non-print mass media messages on FGM/C abandonment a $\dagger$} \\
\hline FGM/C should be stopped & $61 \%$ & $55 \%$ & $77 \%$ & $86 \%$ & $82 \%$ & $67 \%$ \\
\hline $\mathrm{FGM} / \mathrm{C}$ is a harmful practice & $56 \%$ & $57 \%$ & $85 \%$ & $83 \%$ & $86 \%$ & $70 \%$ \\
\hline $\begin{array}{l}\text { FGM/C has bad consequences for women } \\
\text { and girls }\end{array}$ & $53 \%$ & $48 \%$ & $29 \%$ & $60 \%$ & $42 \%$ & $46 \%$ \\
\hline $\begin{array}{l}\text { A girl is born Saleema and should be left } \\
\text { Saleema }\end{array}$ & $55 \%$ & $52 \%$ & $17 \%$ & $54 \%$ & $30 \%$ & $31 \%$ \\
\hline $\begin{array}{l}\text { Cutting is against 'Almawada wa Al- } \\
\text { Rahma' principles }\end{array}$ & $32 \%$ & $27 \%$ & $10 \%$ & $49 \%$ & $26 \%$ & $25 \%$ \\
\hline
\end{tabular}

${ }^{a}$ Differences in proportions between males and females are statistically significant in Gedaref

${ }^{\dagger}$ Among those who reported that they had seen mass media messages about FGM/C

Note: social media includes internet (Facebook, Twitter, Instagram. etc.); multiple responses allowed

The key messages shared through the non-print mass media stated that FGM/C should be stopped, is a harmful practice, and has bad consequences on women's and girls' health. Over half of respondents exposed to non-print mass media had heard multiple messages related to the abandonment of FGM/C (results not shown in the tables). In Gedaref, a smaller proportion of males than females who were exposed to non-print mass media reported that they had seen or heard the following messages: FGM/C has bad consequences for women and girls ( $29 \%$ vs. $60 \%$ ), a girl is born Saleema and should be left Saleema ( $17 \%$ vs. $54 \%)$, and cutting is against "Almawada wa Al-Rahma" principles (10\% vs. $49 \%$ ). Only 30 percent and 31 percent of men and women in Khartoum, respectively, who were exposed to non-print mass media had heard Saleema-related messages through these channels compared to 55 percent and 52 percent of men and women in Al Faw, respectively. Compared to other messages, fewer respondents were exposed to the message that cutting is against "Almawada wa Al-Rahma" principles.

Table 4 summarises the key findings for exposure to FGM/C abandonment messages in printed mass media (newspapers, magazines, posters). The proportion of respondents exposed to these messages via printed media ranged from 47 percent of men in Khartoum to 65 percent of men in Al Faw (Figure 2). Billboards, flyers, and posters were the most common print media channels for these messages. Interestingly, about two fifths of men and women in Gedaref who reported exposure to $\mathrm{FGM} / \mathrm{C}$ abandonment messages via printed media reported seeing these messages in scientific journals, compared to less than 10 percent in other sites. Similarly, a greater proportion of respondents in Gedaref, than in Khartoum or Al Faw, reported seeing these messages in flyers. The proportion of respondents who saw these messages in print media multiple times ranged from 49 percent among men in Khartoum, to 66 percent among women in Gedaref. Differences between males and females in Khartoum with respect to the print media channel(s) used to access messages about FGM/C abandonment were statistically significant.

For specific messages, about one in every two respondents exposed to print media messages had seen: FGM should be stopped, FGM/C is a harmful practice, FGM/C has bad consequences on women and girls' health, and a girl is born Saleema and should be left Saleema. Fewer than five 
percent of respondents had seen print messages declaring that cutting is against "Almawada wa Al-Rahma" principles and in all sites, no men reported that they had seen this particular message.

Table 4. Percentage distribution of survey respondents' exposure to FGM/C abandonment messages via print media, by site and sex

\begin{tabular}{|c|c|c|c|c|c|c|}
\hline & \multicolumn{2}{|c|}{ Al Faw } & \multicolumn{2}{|c|}{ Gedaref } & \multicolumn{2}{|c|}{ Khartoum } \\
\hline & $\begin{array}{c}\text { Male } \\
(\mathrm{N}=97)\end{array}$ & $\begin{array}{l}\text { Female } \\
(\mathrm{N}=86)\end{array}$ & $\begin{array}{c}\text { Male } \\
(\mathrm{N}=94)\end{array}$ & $\begin{array}{c}\text { Female } \\
(\mathrm{N}=93\end{array}$ & $\begin{array}{c}\text { Male } \\
(\mathrm{N}=175)\end{array}$ & $\begin{array}{c}\text { Female } \\
(\mathrm{N}=179)\end{array}$ \\
\hline \multicolumn{7}{|c|}{ Print media channel(s) used to access messages about FGM/C abandonment a $\dagger$} \\
\hline Daily newspapers & $18 \%$ & $10 \%$ & $11 \%$ & $17 \%$ & $23 \%$ & $14 \%$ \\
\hline Magazines & $6 \%$ & $2 \%$ & $6 \%$ & $13 \%$ & $10 \%$ & $2 \%$ \\
\hline Scientific journals & $6 \%$ & $2 \%$ & $37 \%$ & $42 \%$ & $4 \%$ & $1 \%$ \\
\hline Posters & $39 \%$ & $35 \%$ & $9 \%$ & $13 \%$ & $34 \%$ & $43 \%$ \\
\hline Flyers & $10 \%$ & $0 \%$ & $37 \%$ & $58 \%$ & $10 \%$ & $0 \%$ \\
\hline Billboards & $48 \%$ & $57 \%$ & $9 \%$ & $13 \%$ & $46 \%$ & $47 \%$ \\
\hline Others & $0 \%$ & $0 \%$ & $0 \%$ & $0 \%$ & $0 \%$ & $2 \%$ \\
\hline \multicolumn{7}{|l|}{ Frequency of exposure to print media messages ${ }^{\dagger}$} \\
\hline Many times & $63 \%$ & $56 \%$ & $54 \%$ & $66 \%$ & $49 \%$ & $63 \%$ \\
\hline Few times & $37 \%$ & $44 \%$ & $46 \%$ & $34 \%$ & $49 \%$ & $34 \%$ \\
\hline Rarely & $0 \%$ & $0 \%$ & $0 \%$ & $0 \%$ & $1 \%$ & $2 \%$ \\
\hline \multicolumn{7}{|c|}{ Content of the accessed print media messages on FGM/C abandonment ${ }^{\dagger}$} \\
\hline FGM/C should be stopped & $58 \%$ & $61 \%$ & $69 \%$ & $75 \%$ & $68 \%$ & $55 \%$ \\
\hline FGM/C is a harmful practice & $63 \%$ & $61 \%$ & $80 \%$ & $70 \%$ & $65 \%$ & $49 \%$ \\
\hline FGM/C has bad consequences for women and girls & $53 \%$ & $53 \%$ & $61 \%$ & $62 \%$ & $59 \%$ & $40 \%$ \\
\hline A girl is born Saleema and should be left Saleema & $65 \%$ & $57 \%$ & $48 \%$ & $68 \%$ & $60 \%$ & $67 \%$ \\
\hline Cutting is against 'Almawada wa Al-Rahma' principles & $0 \%$ & $4 \%$ & $0 \%$ & $2 \%$ & $0 \%$ & $1 \%$ \\
\hline
\end{tabular}

${ }^{a}$ Differences in proportions between males and females are statistically significant in Khartoum

${ }^{\dagger}$ Among those who reported that they had seen print media messages about FGM/C

Note: Multiple responses allowed

Table 5 summarises the key findings related to exposure to FGM/C abandonment messages through interpersonal communication (e.g., in workshops, advocacy sessions, or home visits). The proportion of respondents who had been exposed to these messages via inter-personal communications ranged from 51 percent among women in Khartoum to 69 percent among men in Gedaref (Figure 2). Among these respondents, the most common way through which these messages were passed was through discussions during daily interactions, including social events like weddings or coffee gatherings. Except for two percent of male respondents in Khartoum, no respondents mentioned hearing $\mathrm{FGM} / \mathrm{C}$ abandonment messages during advocacy sessions. For most respondents, interpersonal communication occurred through expert talks and discussions among community members (results not shown in tables). Except for Khartoum, where 59 percent and 51 percent of male and female respondents, respectively, reported interpersonal communications about FGM/C abandonment a few times, over half of respondents in other areas reported such discussions many times. Differences between males and females in Gedaref with respect to the frequency of exposure to FGM/C abandonment messages through interpersonal communications were statistically significant.

Most respondents had engaged in interpersonal communications on the following issues: FGM should be stopped ( $80 \%$ to $94 \%$ ) and FGM/C is a harmful practice ( $82 \%$ to $91 \%)$. The proportion of respondents who had engaged in interpersonal communications around Saleema ranged from 17 percent among men in Gedaref to 32 percent among women in Al Faw and Gedaref. Except for one percent of women in Khartoum, no respondents reported discussing that cutting is against 'Almawada wa Al-Rahma' principles. Differences between males and females in Gedaref with 
respect to the content of $\mathrm{FGM} / \mathrm{C}$ abandonment messages received through interpersonal communications were statistically significant.

Table 5. Percent distribution of survey respondents' exposure to FGM/C abandonment messages through interpersonal communication, by site and sex

\begin{tabular}{|c|c|c|c|c|c|c|}
\hline & \multicolumn{2}{|c|}{ Al Faw } & \multicolumn{2}{|c|}{ Gedaref } & \multicolumn{2}{|c|}{ Khartoum } \\
\hline & $\begin{array}{l}\text { Male } \\
(\mathrm{N}=97)\end{array}$ & $\begin{array}{l}\text { Female } \\
(\mathrm{N}=86)\end{array}$ & $\begin{array}{l}\text { Male } \\
(\mathrm{N}=94)\end{array}$ & $\begin{array}{l}\text { Female } \\
(\mathrm{N}=93)\end{array}$ & $\begin{array}{c}\text { Male } \\
(\mathrm{N}=175)\end{array}$ & $\begin{array}{l}\text { Female } \\
(\mathrm{N}=179)\end{array}$ \\
\hline \multicolumn{7}{|l|}{ Interpersonal communication channels ${ }^{\dagger}$} \\
\hline Workshops & $14 \%$ & $5 \%$ & $3 \%$ & $6 \%$ & $2 \%$ & $2 \%$ \\
\hline Advocacy sessions & $0 \%$ & $0 \%$ & $0 \%$ & $0 \%$ & $2 \%$ & $0 \%$ \\
\hline Awareness raising & $16 \%$ & $7 \%$ & $14 \%$ & $6 \%$ & $7 \%$ & $5 \%$ \\
\hline Community dialogue & $4 \%$ & $7 \%$ & $17 \%$ & $11 \%$ & $14 \%$ & $8 \%$ \\
\hline Inter-generation dialogue & $4 \%$ & $11 \%$ & $5 \%$ & $13 \%$ & $13 \%$ & $7 \%$ \\
\hline Home visits & $2 \%$ & $5 \%$ & $5 \%$ & $0 \%$ & $2 \%$ & $1 \%$ \\
\hline $\begin{array}{l}\text { Word-of-mouth in daily interaction (including social } \\
\text { events such as weddings or coffee gatherings) }\end{array}$ & $59 \%$ & $66 \%$ & $53 \%$ & $60 \%$ & $58 \%$ & $76 \%$ \\
\hline Other & $2 \%$ & $2 \%$ & $0 \%$ & $2 \%$ & $0 \%$ & $0 \%$ \\
\hline \multicolumn{7}{|c|}{ Method of delivery of interpersonal communication message $(\mathrm{s})^{\dagger}$} \\
\hline Expert talks and discussions & $47 \%$ & $27 \%$ & $39 \%$ & $38 \%$ & $30 \%$ & $34 \%$ \\
\hline Training activities & $0 \%$ & $5 \%$ & $0 \%$ & $0 \%$ & $2 \%$ & $2 \%$ \\
\hline Public lectures & $16 \%$ & $14 \%$ & $16 \%$ & $15 \%$ & $4 \%$ & $3 \%$ \\
\hline Discussions among community members & $53 \%$ & $68 \%$ & $47 \%$ & $68 \%$ & $82 \%$ & $79 \%$ \\
\hline \multicolumn{7}{|c|}{ Frequency participation in interpersonal communication on $\mathrm{FGM} / \mathrm{C}$ abandonment a $\dagger$} \\
\hline Many times & 62 & 56 & 56 & 60 & 41 & 49 \\
\hline Few times & 38 & 44 & 44 & 40 & 59 & 51 \\
\hline \multicolumn{7}{|c|}{ Content of the interpersonal communication messages on FGM/C abandonment a $\dagger$} \\
\hline FGM should be stopped & $80 \%$ & $86 \%$ & $89 \%$ & $94 \%$ & $82 \%$ & $81 \%$ \\
\hline $\mathrm{FGM} / \mathrm{C}$ is a harmful practice & $82 \%$ & $89 \%$ & $89 \%$ & $91 \%$ & $86 \%$ & $85 \%$ \\
\hline $\begin{array}{l}\text { FGM/C has bad consequences on women and girls' } \\
\text { health }\end{array}$ & $57 \%$ & $39 \%$ & $38 \%$ & $45 \%$ & $40 \%$ & $51 \%$ \\
\hline A girl is born Saleema and should be left Saleema & $31 \%$ & $32 \%$ & $17 \%$ & $32 \%$ & $25 \%$ & $27 \%$ \\
\hline $\begin{array}{l}\text { People are unafraid of consequences of change } \\
\text { labandonment }\end{array}$ & $0 \%$ & $0 \%$ & $0 \%$ & $2 \%$ & $0 \%$ & $0 \%$ \\
\hline Cutting is against 'Almawada wa Al-Rahma' & $0 \%$ & $0 \%$ & $0 \%$ & $0 \%$ & $0 \%$ & $1 \%$ \\
\hline
\end{tabular}

${ }^{a}$ Differences in proportions between males and females are statistically significant in Gedaref

${ }^{\dagger}$ Among those who reported that they had interpersonal discussions on FGM/C abandonment Note: Multiple responses allowed

Study findings suggest that respondents were more aware of the Saleema campaign than the M\&R campaign. Although a lower proportion of respondents reported that they had been exposed to FGM/C abandonment messages via print media than non-print mass media (Figure 2), as shown in Figure 3, a higher proportion of the former reported exposure to Saleema messages. 
Figure 3. Percent distribution of survey respondents' exposure to Saleema messages via different delivery channels, by site and sex

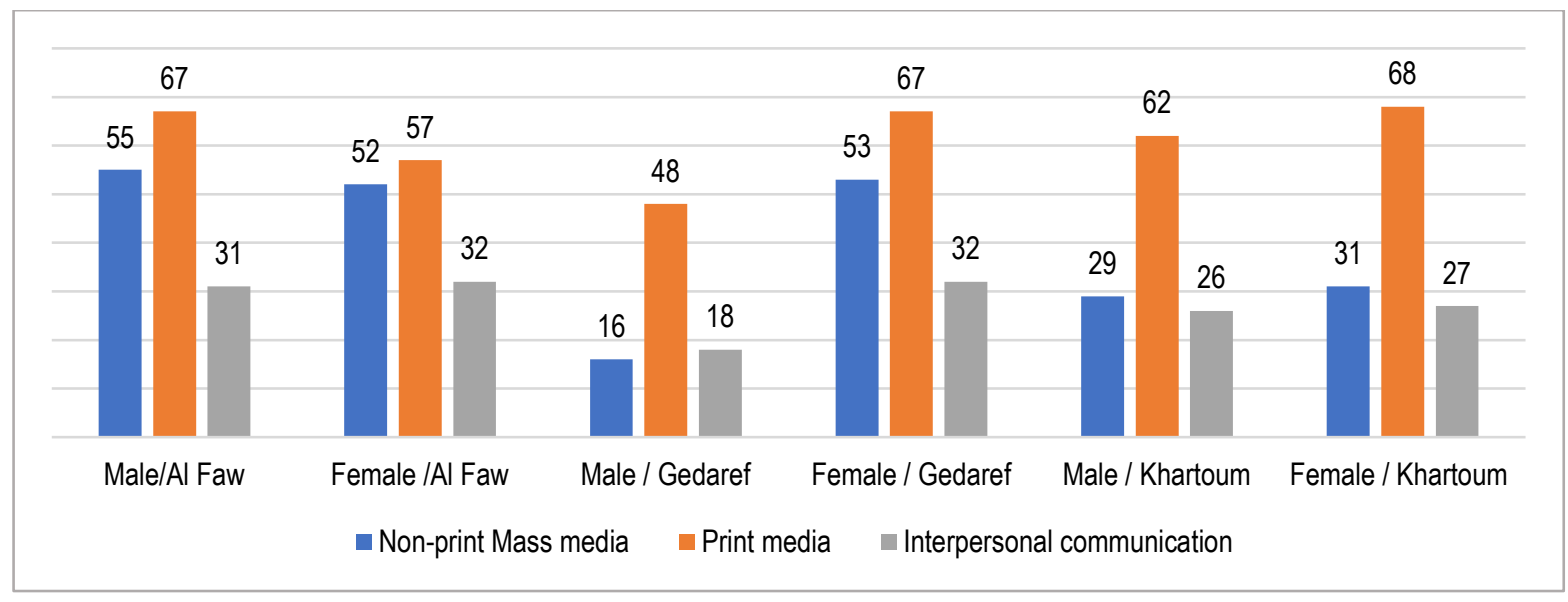

\section{Clarity and Ease of Understanding Messages}

Table 6 summarises respondents' perceptions of the suitability of message transmission timing. Most respondents (97\% to $90 \%$ ) reported that timings were very suitable or suitable. In Al Faw a greater proportion of women $(10 \%)$ than men $(3 \%)$ felt that the timing of these messages was unsuitable. Most respondents who had seen FGM/C abandonment posters found their placement very suitable or suitable. In Al Faw, where a greater proportion of respondents were exposed to poster messages, 11 percent of males and 17 percent of females felt their placements were unsuitable.

Table 6. Percent distribution of survey respondents' perceptions of the suitability of the timing of transmission messages on FGM/C abandonment and the placement of anti-FGM/C posters, by site and sex

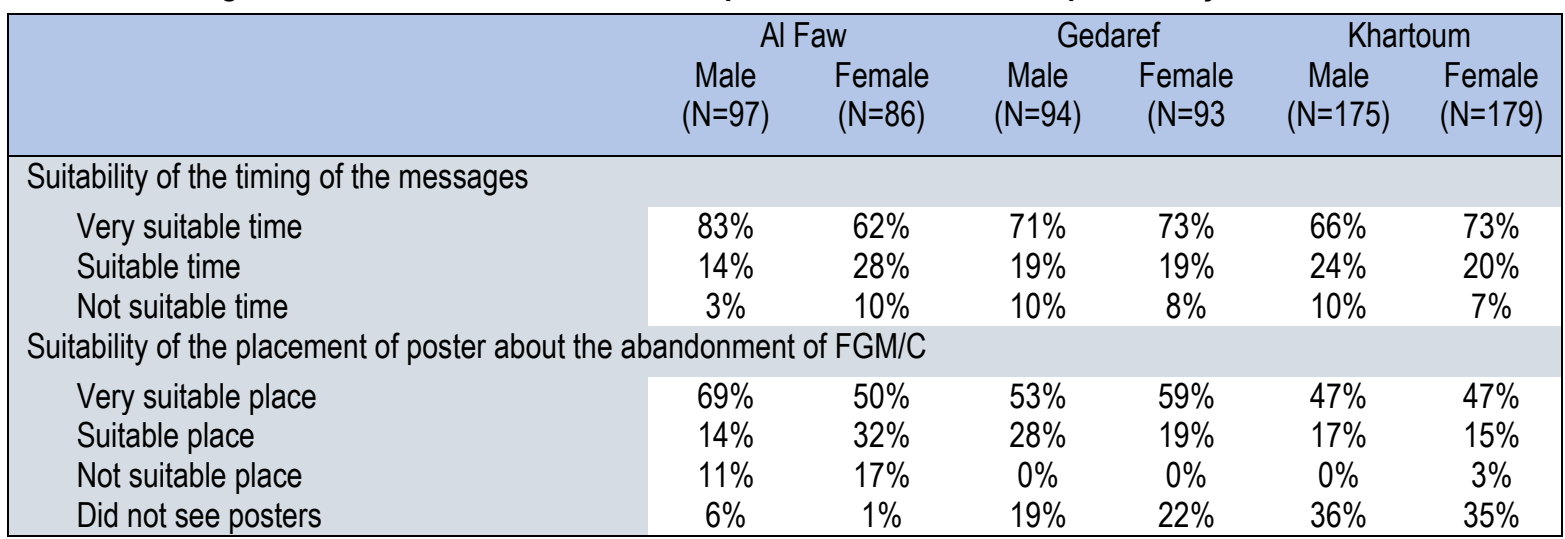

Table 7 summarises respondents' feedback about what they understood to be the key FGM/C abandonment messages communicated through the different communication channels. Irrespective of the communication channel, the majority of respondents (78\% to $100 \%)$ reported that they understood that people should stop FGM/C because it is harmful to girls' and women's health. The next most widely understood message was that people should stop FGM/C because 'a girl should be Saleema' ( $28 \%$ to $70 \%$ ). Except for one female respondent in Khartoum who had engaged in interpersonal discussions about FGM/C abandonment, no other respondent reported that they had understood that people should stop FGM/C because cutting is against the principles of 'Almawada wa Al-rahma'. Among respondents exposed to anti-FGM/C messages via non-print 
mass media and print media, a slighter higher proportion of respondents in Gedaref understood that the practice should be stopped because it is against the law.

Few respondents (results not shown in tables) reported that they had consulted other people after their exposure to $\mathrm{FGM} / \mathrm{C}$ abandonment messages. Survey respondents noted that the trustworthiness of the messages was influenced by whether they trusted the source of message (radio, TV, internet), the attractiveness of the message's source (newspapers, magazines, photos in posters), the clarity of the benefits of abandonment presented, the clarity of illustrative pictures in the messages, and agreement with the source perspective (results not shown in tables).

Table 7. Distribution of respondents according to elements understood from abandonment messages, by site and sex

\begin{tabular}{|c|c|c|c|c|c|c|}
\hline \multirow[b]{2}{*}{ Elements understood from abandonment messages } & \multicolumn{2}{|c|}{ Al Faw } & \multicolumn{2}{|c|}{ Gedaref } & \multicolumn{2}{|c|}{ Khartoum } \\
\hline & Male & Female & Male & Female & Male & Female \\
\hline \multicolumn{7}{|l|}{ Non-print mass media } \\
\hline $\begin{array}{l}\text { We should stop FGM/C because it is harmful to girls' } \\
\text { and women's health }\end{array}$ & $92 \%$ & $97 \%$ & $91 \%$ & $94 \%$ & $92 \%$ & $86 \%$ \\
\hline ...because it is not a religious practice & $19 \%$ & $18 \%$ & $18 \%$ & $21 \%$ & $6 \%$ & $14 \%$ \\
\hline ...because a girl should be Saleema & $35 \%$ & $48 \%$ & $28 \%$ & $46 \%$ & $43 \%$ & $45 \%$ \\
\hline ...because it is against the law & $23 \%$ & $20 \%$ & $35 \%$ & $29 \%$ & $18 \%$ & $19 \%$ \\
\hline & $n=75$ & $n=60$ & $n=78$ & $n=63$ & $n=125$ & $n=118$ \\
\hline \multicolumn{7}{|l|}{ Print media } \\
\hline $\begin{array}{l}\text { We should stop FGM/C because it is harmful to girls' } \\
\text { and women's health }\end{array}$ & $89 \%$ & $92 \%$ & $83 \%$ & $89 \%$ & $78 \%$ & $65 \%$ \\
\hline ...because it is not a religious practice & $23 \%$ & $14 \%$ & $26 \%$ & $23 \%$ & $12 \%$ & $20 \%$ \\
\hline ...because a girl should be Saleema & $42 \%$ & $49 \%$ & $31 \%$ & $43 \%$ & $44 \%$ & $58 \%$ \\
\hline ...because it is against the law & $19 \%$ & $14 \%$ & $24 \%$ & $21 \%$ & $11 \%$ & $18 \%$ \\
\hline & $n=62$ & $n=51$ & $n=54$ & $n=53$ & $n=82$ & $n=92$ \\
\hline \multicolumn{7}{|l|}{ Interpersonal communications } \\
\hline $\begin{array}{l}\text { We should stop FGM/C because it is harmful to girls' } \\
\text { and women's health }\end{array}$ & $100 \%$ & $91 \%$ & $97 \%$ & $91 \%$ & $89 \%$ & $90 \%$ \\
\hline ...because it is not a religious practice & $31 \%$ & $41 \%$ & $41 \%$ & $32 \%$ & $25 \%$ & $27 \%$ \\
\hline ...because a girl should be Saleema & $55 \%$ & $70 \%$ & $55 \%$ & $62 \%$ & $49 \%$ & $57 \%$ \\
\hline ...because it is against the law & $22 \%$ & $27 \%$ & $16 \%$ & $23 \%$ & $16 \%$ & $15 \%$ \\
\hline ...because cutting is against Almawada wa Al Rahma & $\begin{array}{c}0 \% \\
n=49\end{array}$ & $\begin{array}{c}0 \% \\
n=44\end{array}$ & $\begin{array}{c}0 \% \\
n=64\end{array}$ & $\begin{array}{c}0 \% \\
\mathrm{n}=47\end{array}$ & $\begin{array}{c}0 \% \\
n=92\end{array}$ & $\begin{array}{c}1 \% \\
n=91\end{array}$ \\
\hline
\end{tabular}

\section{Decision Making}

Table 8 shows the decisions of respondents for FGM/C abandonment after exposure to FGM/C abandonment messages through different channels. Most respondents (70\% to $100 \%)$ stated they had decided not to practice FGM/C following exposure to these messages. For all sites, a greater proportion of women reported still supporting FGM/C after exposure to abandonment messages, with higher proportions in Khartoum than other sites still supporting the practice.

Table 8. Distribution of respondent decisions due to exposure to messages in different channels, by site and sex

\begin{tabular}{|lcccccc|}
\hline \multirow{2}{*}{$\begin{array}{l}\text { Decision after exposure to abandonment } \\
\text { messages }\end{array}$} & \multicolumn{2}{c}{ Al Faw } & \multicolumn{2}{c}{ Gedaref } & \multicolumn{2}{c|}{ Khartoum } \\
\hline $\begin{array}{l}\text { Non-print mass media } \\
\text { Reached a decision not to practise FGM/C }\end{array}$ & Female & Male & Female & Male & Female \\
I preserved my opinion on FGM as a bad practice & $96 \%$ & $88 \%$ & $91 \%$ & $83 \%$ & $76 \%$ & $72 \%$ \\
but hesitant to decide abandonment & $1 \%$ & $7 \%$ & $6 \%$ & $11 \%$ & $16 \%$ & $13 \%$ \\
I still support FGM/C practice & $3 \%$ & $5 \%$ & $3 \%$ & $6 \%$ & $8 \%$ & $15 \%$ \\
Print media & $\mathrm{n}=75$ & $\mathrm{n}=60$ & $\mathrm{n}=78$ & $\mathrm{n}=63$ & $\mathrm{n}=125$ & $\mathrm{n}=118$ \\
Reached a decision not to practise FGM/C & $92 \%$ & $92 \%$ & $90 \%$ & $81 \%$ & $87 \%$ & $70 \%$ \\
\hline
\end{tabular}




\begin{tabular}{|c|c|c|c|c|c|c|}
\hline \multirow[b]{2}{*}{$\begin{array}{l}\text { Decision after exposure to abandonment } \\
\text { messages }\end{array}$} & \multicolumn{2}{|c|}{ Al Faw } & \multicolumn{2}{|c|}{ Gedaref } & \multicolumn{2}{|c|}{ Khartoum } \\
\hline & Male & Female & Male & Female & Male & Female \\
\hline \multirow{2}{*}{$\begin{array}{l}\text { I preserved my opinion on FGM as a bad practice } \\
\text { but hesitant to decide abandonment } \\
\text { I still support FGM/C practice }\end{array}$} & $4 \%$ & $2 \%$ & $8 \%$ & $13 \%$ & $4 \%$ & $17 \%$ \\
\hline & $\begin{array}{c}4 \% \\
n=62\end{array}$ & $\begin{array}{c}7 \% \\
n=51\end{array}$ & $\begin{array}{c}2 \% \\
n=54\end{array}$ & $\begin{array}{c}6 \% \\
n=53\end{array}$ & $\begin{array}{c}9 \% \\
n=82\end{array}$ & $\begin{array}{l}13 \% \\
n=92\end{array}$ \\
\hline \multirow{3}{*}{$\begin{array}{l}\text { Interpersonal communications } \\
\text { Reached a decision not to practise FGM/C } \\
\text { I preserved my opinion on FGM/C as a bad } \\
\text { practice-but hesitant to decide abandonment } \\
\text { I still support FGM/C practice }\end{array}$} & $100 \%$ & $86 \%$ & $90 \%$ & $80 \%$ & $80 \%$ & $77 \%$ \\
\hline & $0 \%$ & $5 \%$ & $3 \%$ & $14 \%$ & $9 \%$ & $7 \%$ \\
\hline & $\begin{array}{c}0 \% \\
n=49\end{array}$ & $\begin{array}{c}8 \% \\
n=44\end{array}$ & $\begin{array}{c}6 \% \\
n=64\end{array}$ & $\begin{array}{c}7 \% \\
n=47\end{array}$ & $\begin{array}{l}11 \% \\
n=92\end{array}$ & $\begin{array}{l}16 \% \\
n=91\end{array}$ \\
\hline
\end{tabular}

\section{Discussion}

In response to the Sudanese government's endorsement of the eradication of FGM/C, several nationwide campaigns to encourage $\mathrm{FGM} / \mathrm{C}$ abandonment have been implemented. This study assessed the design and implementation of existing SMC programmes in Sudan to examine the application of SM principles and to draw lessons to improve existing programmes and inform the design and scale up of SMCs. Hornik and Yanovitsky (2003) have argued that the design and evaluation of complex interventions, such as SMCs, should be guided by a theory of change that outlines the variables to be measured or changed as well as the pathways of change. However, we found that very few of the ongoing SMCs for FGM/C abandonment included in this study met Andreasen's (1994) criteria for best-practices in SM due to the limited knowledge and application of SM theories and principles, such as the '4Ps', in the design and implementation of these campaigns. For many actors, understanding of marketing concepts was only perceived from the business angle and the link to social/behavioural change seemed limited.

The limited use of theory and SM principles may be attributed to the relatively short experience with SM approaches and lack of capacity building programmes ensuring that those who develop and implement campaigns understand their theoretical and conceptual foundations in addition to social norms and behaviour change theories. Although extensive training was conducted by Saleema SMC targeting some of the implementing partners, the results of this training seemed limited in the theoretical elements. Further, the high turnover of the trained partners/institutions may limit sustained application of knowledge and skills acquired. It is important to emphasise that there are an increasing number of actors engaged in FGM/C abandonment, especially NGOs and CBOs, mostly engaged as implementing partners after capacity assessment done by funders. It is evident that SM knowledge and skills are not part of the assessment.

Pre-testing, monitoring, and evaluation are core to the application of the SM approach (Andreasen 1994, Lee and Kotler 2011). Most key informants noted that these aspects were not adequately addressed during the design and implementation of many campaigns. Notable exceptions included Saleema, which had a monitoring strategy outlined at the design phase, and the M\&R SMC, which had an M\&E framework. Limited knowledge about the principles and steps of application of the SM approach may underlie limited use of pre-tests to ensure relevance and suitability of $\mathrm{FGM} / \mathrm{C}$ messages for people's needs and FGM/C perception. These findings may reflect an organisational culture in some governmental institutions and NGOs in Sudan that downplay the importance of M\&E. Monitoring and evaluation systems are often not a prerequisite for funding of interventions and, therefore, these aspects may receive less attention. Results suggest that many staff involved in $\mathrm{FGM} / \mathrm{C}$ abandonment interventions have very limited capacities to design and implement M\&E systems. 
An important element of SMCs is audience segmentation at three levels-upstream (policymakers, media, etc., who can create enabling environments), midstream (influencers such as friends and role models), and downstream (individuals engaged in the action to be changed) (Kotler et al 2013). The findings show that while Saleema introduced new techniques and implementation strategies to influence community behaviour change, or downstream audiences, there was limited focus on midstream and upstream actors including political leaders, religious institutions, policy makers, and other stakeholders who can serve as role models and play a major role in influencing policy change for abandonment. Focus on 'downstream' actors may be due to the fact most interventions are conducted by NGOs that may have limited access to policy makers or state-controlled media. Innovative techniques and implementation strategies introduced by Saleema enabled implementers to engage 'midstream' actors such as local singers, poets, and community and religious leaders, however. Further research is needed to understand how programmes can create complementarity of interventions at the three levels (Kotler et al 2013).

The expanded list of marketing 'Ps' outlines the importance of partnerships, which enable programmes to draw on the strengths of different actors. All the SMC designers and implementers reported that they implemented their interventions in partnerships and emphasised the value of these partnerships. This is an important result demonstrating positive impact of partnerships that are built among international and national partners and strengthened during implementation of interventions. Despite the great efforts of the Project Sudan Free of FGM/C 2013 to 2018, which supported capacity building for coordination among implementing actors, it was not evident how these partnerships were visualised to promote coordination and complementarity of approaches and activities, especially for the Saleema and M\&R campaigns. Further, some key informants noted that weak political will in some of the institutions and limited funding as obstacles to effective partnerships and coordination with impacts on the continuity of interventions, outreach, and persistent visibility of SMCs. Limited funding leads to inadequate sustainable exposure to SMCs' products/messages to motivate the individual and the whole community and help create the critical mass that will make those who think of adopting the innovation (new norm of not cutting) feel safe from social disapproval and sanctions (Rogers 1995, 2003, Mackie, Francesca, Shakya, Denny 2015). For SMCs to achieve the goal of change of norms and behaviour for social good (Kotler and Zatlan 1971) there must be continuity because behaviour change takes a considerably long time. But more significantly, this limitation reaffirms that intervention design and planning is not done with a clear vision to promote behaviour change according to stages of 'action' and 'maintenance' guided by a theory of change.

Most SMC designers and implementers used multiple channels including non-print mass media, printed media, and inter-personal communications to deliver messages to the target audiences. Not surprisingly, therefore, many respondents had been exposed to different FGM/C abandonment campaigns through a variety of channels. The use of multiple channels is a known SM tool (CPRD 2009) emphasised by the Saleema campaign. The variation in products and tools are necessitated by the diversity of context; ethnicity, class, education, and regional diversity between and within communities in Sudan. Although interpersonal communication may be deemed to be more influential since it allows clarification and exchange of views, it is a costly approach since it needs well trained facilitators from the targeted communities. While relatively few survey respondents had been exposed to FGM/C abandonment messages via social media, the results suggest that the internet is a potential channel for improving outreach considering the rapid growth in the telecommunication sector in Sudan and recent popularity of social media as a source of information exchanged in our everyday interactions. Further, counter to concerns by the key informants about the dilution of $\mathrm{FGM} / \mathrm{C}$ messages that may be integrated into reproductive and maternal health campaigns, most survey respondents appeared to understand the key messages surrounding 
FGM/C. However, concerns about the dilution of FGM/C messages remain valid in a context where funding specifically earmarked for $\mathrm{FGM} / \mathrm{C}$ abandonment programmes is limited.

Although many survey respondents reported exposure to FGM/C abandonment campaigns, the survey results suggest that they were more aware of the Saleema campaign than the M\&R campaign. This difference may partly stem from the fact that the Saleema campaign has been implemented for a longer duration than the M\&R campaign. In addition, unlike Saleema, which has a branded campaign, partners involved in the M\&R campaign design unbranded messages based on M\&R religious (Islamic) principles of mercy and compassion. As such, most study respondents may not have been able to recognise M\&R-related messages. These findings are in line with recent evidence demonstrating the important role that branding, which has been defined as the process of "attaching a label" (for identification) and "meaning" (for understanding) to a product, service, person, idea, etc.' (Keller 1998), plays in enabling individuals to make meaningful associations with messages (Gordon, Zainuddin, Magee 2016). However, further research on the application of branding theories to SM programmes is warranted.

Although most of the respondents stated that they had made a decision about abandonment following their exposure to FGM/C abandonment messages, few reported that they had consulted their reference groups. In areas where interactive methods were used for the diffusion of information at community levels, and where collective commitments are confirmed, respondents may not need to consult others because the fear of negative social sanctions is low. However, in areas where such methods are not used, the influence of reference groups may need to be considered. That a substantial number of study respondents stated that they had decided to abandon $\mathrm{FGM} / \mathrm{C}$ following exposure to messages should be interpreted in light of the significantly large number of anti-FGM/C interventions. For example, for decades, Al Faw has been a focus area for several actors who design and implement FGM/C interventions. These include the Reproductive Health Directorate in Gedaref, the College for Community Development at the University of Gedaref (CCD), Friends of Peace and Development Organization (FPDO), and Sakina Organization for Combating Harmful Traditional Practices, a CBO in Gedaref State that has benefited from intensive training from the CCD. As such, people have been frequently exposed to messages and products and have had the opportunity to deliberate and discuss with their reference groups; all of which adds to their knowledge and motivation to support abandonment. From an SM perspective, 'a campaign must have a significant duration to impact the target population' (Hafstad et al 1997 cf. GPRD 2009).

The results demonstrated that people exposed to interventions made different decisions along the behaviour change model. These results related to the loud voices for abandonment of the practice that started decades ago and intensified with Saleema campaigns. This is coupled with changing dynamics in the socio-economic context related to the spread of education, increased use of community dialogue, and exposure to the international media. Accordingly, there are the willing adherents to the practice and these represent the influence of the emerging religiously conservative groups. Reluctant abandoners and contemplators may indicate the weak influence of message and limited number and efforts of the 'critical mass' to reach a 'tipping point', or negative influence of their reference group. All can be related to the discontinuity and lack of coordination of campaigns. Both shortcomings are, to a great extent, related to limited funding. From an SM perspective, 'a campaign must have a significant duration to impact the target population' (Hafstad et al 1997 cf. GPRD 2009). It was not easy to have evidence for 'willing abandoner', except some stories of uncut adult females, revealed in interviews, as there is still a fear of social disapproval and sanctions. 


\section{Implications for Practice, Funding, Research, and Policy}

\section{Programme Implications}

- For social marketers to design and implement programmes that influence norms and create behavioural change towards abandonment, there is a need to improve the quality of formative research and make use of research knowledge and evidence in both the design and implementation of SMCs to end FGM/C.

- Study findings underscore the need for increased investments in building the capacity of programme staff to use marketing concepts and ensure that programme design is based on SMC principles. Programmes need to invest in M\&E capacity building.

- It is apparent that SMCs are focusing on downstream levels, such as grassroots communities and individuals, and overlooking midstream and upstream levels. There is a need to target individuals, institutions, organisations, at midstream and upstream levels, who create an enabling environment for behaviour change and ensure policy support for abandonment.

- There are an increasing number of programme interventions for FGM/C abandonment in Sudan. In Sudan, UNFPA, UNICEF, and WHO should maintain the catalytic nature of their joint programmes to continue working with current implementing partners, while considering the potential for innovation and diversification inherent in engaging with emerging, new, and young actors such as youth organisations, especially at a state level. Again, the agencies and their partners need to reconsider complementarities of Saleema and M\&R approaches and encourage and motivate partners to work on a coordinated approach.

\section{Investment Implications}

- Study findings underscore the need for increased funding to ensure quality, outreach, and inclusion of individuals and communities for FGM/C abandonment. This calls for increased investments to be availed and allocated to communities based on their needs as reflected by community assessments.

- Given national funding limitations, irregularities, and constraints to its accessibility at state level, UNFPA, WHO, and UNICEF should encourage existing or potential donors interested in contributing to $\mathrm{FGM} / \mathrm{C}$ abandonment work to commit to predictable, longer-term coordinated financing.

- The leading government institutions should try to raise funds from national and state governments and public institutions to reduce dependency on donors.

- NGOs should be encouraged to develop fund-raising strategies that include outreach to the private sector to motivate them to contribute financially as part of corporate social responsibility to these endeavours.

\section{Research Implications}

- Given the importance of the segmentation of audiences at the upstream, midstream, and downstream levels, further research is needed to understand how programmes ensure the complementarity of interventions at the three levels.

- Given the important role that branding may play in SM, further research on the application of branding theories to SM programmes is warranted.

- In-depth analysis and understanding of the holistic approaches that respond to community needs while integrating FGM/C abandonment in development programmes remain needed to guide replication and scale up. 
- Further assessment of the potential for using social media and chat rooms on mobile phones as a communication channel is warranted.

\section{Policy Implications}

- There is a strong need for consistent policies that create an enabling environment for the abandonment of all forms of FGM/C.

- Policies are also needed to guide governmental actors as well as the various relevant national institutions such as religious institutions, the media, government financial institutions, and the private sector to support SM interventions.

- The need remains for the enactment of an anti-FGM/C law and the formulation of a national funding strategy that supports policy change. At the individual level, policy makers can become role models and positive influencers within their networks and communities. 


\section{References}

Ahmed, S., S.A. Hebshi, B. Nylund. 2009. An in-depth analysis of the social dynamics of abandonment of FGM/C. Special series on social norms and harmful practices. Sudan. New York: UNICEF Innocenti Centre, 1-25.

Andreasen, A.R. 1994. Social marketing: its definition and domain. Journal of Public Policy \& Marketing, 13(1): 108-114.

Bedri, N.M. 2012. Ending FGM/C through evidence based advocacy in Sudan. Omdurman: Ahfad University for Women, 1-16.

Boddy, J. 1982. Womb as oasis: The symbolic context of pharaonic circumcision in rural northern Sudan. American Ethnologist 9(4): 682-698.

Bridges, T. and N. Farland. 2003. Social marketing: Behaviour change marketing in New Zealand. Wellington: The Bridge and Senate. http://senateshj.com/sites/default/files/BRI249\%20Soc-Marketing.pdf

Brown, K., D. Beecham, H. Barrett. 2013. The applicability of behaviour change in intervention programmes targeted at ending female genital mutilation in the EU: Integrating social cognitive and community level approaches, Obstetrics and Gynaecology International, http://dx.doi.org/10.1155/2013/324362

Central Bureau of Statistics. 2010. Sudan Household Health Survey (SHHS), Khartoum: Republic of Sudan.

Central Bureau of Statistics (CBS), UNICEF Sudan. 2016. Multiple Indicator Cluster Survey 2014 of Sudan, Final Report. Khartoum, Sudan: UNICEF and CBS.

Center for Prevention Research and Development (CPRD). 2009. Communication or social norms campaigns research summary (substance abuse prevention focused). Champaign, IL: Center for Prevention Research and Development, Institute of Government and Public Affairs, University of Illinois.

Gordon, R., N. Zainuddin, C. Magee. 2016. Unlocking the potential of branding in social marketing services: Utilising brand personality and brand personality appeal. Journal of Services Marketing 30(1): 48-62.

Grbich, C. 2013. Qualitative data analysis: An introduction. SAGE Publication Ltd (pp15-91).

Grier, S. and C.A. Bryant. 2005. Social marketing in public health. Annual Review of Public Health 26: 319-339.

Gruenbaum, E. 2001. The female circumcision controversy: An anthropological perspective. Philadelphia: University of Pennsylvania Press.

Hamilton, A. and N.B. Kandala. 2015. Geography and correlates of attitude toward female genital mutilation (FGM) in Sudan: What can we learn from successive Sudan opinion poll data? Spatial and Spatio-temporal Epidemiology 16, 59-76.

Hornik, R.C. and I. Yanovitzky. 2003. Using theory to design evaluations of communication campaigns: The case of the National Youth Anti-Drug Media Campaign. Communication Theory 13(2): 2014-224.

Keller, K.L. 1998. Branding perspectives on social marketing. In J.W. Alba \& J.W. Hutchinson (eds). Advances in Consumer Research. Provo, UT: Association for Consumer Research, 299-302. 
Kotler, P. and G. Zaltman. 1971. Social Marketing: An Approach to Planned Social Change. Journal of Marketing 35: 3-12.

Kotler, P., M. Polonsky, G. Hardings. 2013. Social marketing transformed: Social marketing in a period of social change. European Journal of Marketing 47(9): 1376-1298.

Lee, N. and P. Kotler. 2011. Social Marketing: Influencing Behaviour for Good. Sage, 1-5.

Lefebvre, R.C. 2012. Transformative social marketing: Co-creating the social marketing discipline and brand. Journal of Social Marketing 2(2): 118-129.

http://dx.doi.org/10.1108/20426761211243955

Mackie, G. and J. LeJeune. 2009. Social dynamics of abandonment of harmful practices: A new look at the theory. In Special Series on Social Norms and Harmful Practices. Florence: UNICEF, Innocenti Research Centre, 1-29.

Mackie, G., M. Francesca, H. Shakya, E. Denny. 2015. What are social norms? How are they measured? UNICEF, Center on Global Justice. San Diego: University of California, 4-94.

National Ministry of Health and Central Bureau of Statistics. 2011. Sudan Household Survey 2010 Summary Report, 1-5.

National Centre for Social Marketing. 2009. Review of social marketing within public health regional settings. London: National Social Marketing Centre, 4-18.

Oldenburg, B. and K. Glanz. 2008. Diffusion of Innovation' in Health Behaviour and Health Education: Theory, Research and Practice. London: John Wiley and Sons.

Rogers, E.M. 1995. Diffusion of Innovation. New York: The Free Press, 204-251.

Rogers, E.M. 2003. Diffusion of Innovation, $5^{\text {th }}$ ed. New York: The Free Press, 283.

Sahl, I.M. 2016. Al Mawada Wa Al Rahma Initiative: Assessment of the implementation of the approach for the period 2013 to 2016. Sudan: UNFPA, 12.

Shell-Duncan, B. and Y. Herniund. 2006. Are there "stages of change" in the practice of female genital cutting? Qualitative research findings from Senegal and The Gambia. African Journal of Reproductive Health 10(2): 57-71.

Shell-Duncan, B. 2001. The medicalization of female "circumcision": Harm reduction or promotion of a dangerous practice? Social Science \& Medicine 52(7): 1013-1028.

Strauss, A. and J. Corbin. 1967. Grounded Theory in Practice. Thousand Oaks, CA: Sage.

Thiam, M. 2016. Female genital mutilation/cutting (FGM/C) and child marriage in Sudan: Are there any changes taking place? An in-depth analysis using Multiple Indicators Cluster Surveys (MICS) and Sudanese Household and Health Surveys (SHHSs). Sudan: UNICEF, 16-17.

Tønnessen, L. 2011. Beyond numbers? Women's 25\% parliamentary quota in post-conflict Sudan. Journal of Peace, Conflict and Development 17: 43-62.

UNFPA. 2012. Ending Female Genital Mutilation/Cutting in Sudan, 1-4.

UNICEF. 2014. Female Genital Mutilation/Cutting: A statistical overview and exploration of the dynamics of change. New York: UNICEF.

WHO. 2014. World Health Organization Fact sheet 241.

WHO. 2017. World Health Organization Fact sheet 241, Updated February 2017. www.who.int/mediacentre/factsheets/fs241/en 